\title{
ARQUEOLOGÍA DE LAS LLAQTAS DEL VALLE DEL APURÍMAC: CONTRIBUCIÓN AL ESTUDIO DE LA TERRITORIALIDAD DE LAS COMUNIDADES ALDEANAS SERRANAS EN LOS ANDES PREHISPÁNICOS
}

\author{
ARCHAEOLOGY OF THE LLAQTAS OF THE APURÍMAC VALLEY: A \\ CONTRIBUTION TO THE STUDY OF THE TERRITORIALITY OF THE \\ MOUNTAINOUS VILLAGE COMMUNITIES IN THE PREHISPANIC ANDES
}

Thibault Saintenoy ${ }^{1,2,3}$

\begin{abstract}
La identificación de las comunidades a partir de la organización socioespacial de su territorio es un interés clásico, pero no menos problemático de los estudios regionales en arqueología. Dentro del contexto andino, el problema es particularmente dificultoso debido a la flexibilidad de escala demográfica e identitaria del concepto vernáculo de ayllu tal como aparece en las fuentes etnohistóricas y etnográficas, así como por el hecho de la paradigmática espacialidad discontinua e interdigitada del poblamiento de los territorios descritos por las mismas fuentes.

El análisis del poblamiento prehispánico tardío (siglo XI a siglo XVI d.C.) del valle del Apurímac (Cusco, Perú) es una oportunidad para contribuir en esta discusión a partir de informaciones inéditas referentes a la estructura territorial de las comunidades aldeanas asentadas en uno de los más profundos valles interandinos ubicado al pie de la cordillera de Vilcabamba. El estudio combina análisis espacial, ecología cultural, arqueología del paisaje y analogía etnográfica para proponer una lectura multifactorial y multiescalar de los patrones de asentamiento prehispánicos. A escala local, el estudio pone en evidencia un tipo de red de asentamientos recurrente que podría corresponder al esquema socioespacial de comunidad aldeana. A escala regional, el estudio muestra, desde una perspectiva bottom-up, la heterogeneidad del poblamiento del valle, el mismo que ilustra la compleja situación geopolítica expresada por las fuentes etnohistóricas sobre este espacio territorial intermedio vecino al corazón del Tawantinsuyu. Desde el punto de vista teórico, los datos permiten desarrollar una reflexión acerca de los fundamentos territoriales de las comunidades aldeanas prehispánicas tardías.
\end{abstract}

Palabras claves: territorialidad, comunidad, patrón de asentamiento, red de asentamientos, periodo Intermedio Tardío, Inca.

A classic interest among archaeological regional studies is identifying communities based on the socio-spatial organization of a territory. In the Andes, the problem is topical due to the flexibility of the vernacular concept of ayllu, in terms of its demographic and identitarian scale, as it appears in ethnohistoric and ethnographic sources; and because of the interdigitated and discontinuous spatiality of the territories described by these sources.

The analysis of the late pre-Hispanic settlement pattern (XI to XVI century AD) of the Apurímac valley (Cuzco, Peru), presents itself as an opportunity to contribute in this classic discussion. Based on both archaeological surveys and ethnographic data, this article deals with the territorial structure of the village communities of one of the deepest Andean valleys located at the foot of the Vilcabamba Cordillera. The study combines geospatial modeling, cultural ecology, landscape archaeology and ethnographic analogy to suggest a multi-factorial and multi-scalar reading of settlement patterns. At the local scale, analysis and modeling show a kind of recurrent settlement network that could form a socio-spatial scheme of the Andean dispersed village community. At the regional scale, the study shows, according to a bottom-up perspective, the heterogeneity of the valley occupation which corresponds to the complex geopolitical context depicted in the ethnohistorical sources about this intermediate area located close to the Inca heartland. From a theoretical point of view, the data allows a reflection about the territorial basis of the late pre-Hispanic village communities.

Key words: Territoriality, community, settlement pattern, settlement network, Late Intermediate Period, Inca.

\footnotetext{
1 Centro de Investigaciones del Hombre en el Desierto (CONICYT), Arica, Chile.

2 Archeologie des Ameriques (ARCHAM), Centre National de la Recherche Scientifique, Paris, Francia.

$3 \quad$ Universidad de Tarapacá, Arica, Chile. tsaintenoy@gmail.com
} 
Llaqta es un término quechua de origen prehispánico, que designaba de manera genérica los asentamientos habitacionales en los Andes Centrales. Los primeros diccionarios bilingües dan por equivalente el término castellano "pueblo" (Gonzáles Holguín 1989 [1608]; Santo Tomás 1951 [1560]). Pero en los archivos coloniales "pueblo" designaba indistintamente asentamientos habitacionales de una decena a un millar de casas. En efecto, los españoles prestaron un interés limitado a la estructura territorial indígena (Saignes 1991). De hecho, tres décadas después de la conquista fue implementada una vasta política de reordenamiento territorial, correspondiente a la fundación de nuevos asentamientos, sedes de la administración colonial y de la Iglesia, donde los indígenas tenían ya la obligación de residir (Cook 1975; Mumford 2012). Por este motivo no se conoce bien la estructura territorial de las comunidades aldeanas de los Andes prehispánicos ni las instituciones sociopolíticas relacionadas (Salomon 1991).

Explicar los modos de organización sociopolítica y territorial del mundo prehispánico a partir de evidencias materiales es una temática clásica de la arqueología andina tradicionalmente abordada por los estudios de patrones de asentamiento (Fish 1999; Kowalewski 2008; entre otros). Una de las problemáticas centrales de estos estudios se relaciona con la identificación de la comunidad, es decir, del colectivo social cuyos miembros viven juntos y/o comparten una identidad común. Dos puntos de vista divergen en cuanto a la naturaleza de la noción de comunidad y a su legibilidad en el registro arqueológico. La primera, de tendencia conductista y materialista, considera como indicador el grado de interacción social, como puede ser inferido de la espacialidad de los vestigios del poblamiento, la cual generalmente se interpreta según modelos teóricos de organización sociopolítica y en función de las características del escenario geoambiental (Peterson y Drennan 2005). La segunda preconiza una postura relativista, heredada de los estudios de casos históricos y etnográficos, haciendo hincapié en los referentes culturales y en las estructuras tradicionales en las que se basan y se reproducen las comunidades (Molinié Fioravanti 1978, 1985), otorgando un papel más o menos significativo a la agencia de individuos en dichos procesos. Pero estos dos enfoques complementarios son a menudo contrapuestos, no solamente por relacionarse con perspectivas teóricas a veces divergentes (Isbell
2000), sino también por el hecho de estar basados en distintos campos de datos. Efectivamente, en ausencia de informaciones emic sobre las culturas premodernas, la arqueología está generalmente limitada a desarrollar un enfoque interaccionista que privilegia el territorio a la comunidad como objeto de estudio. El interés radica entonces en hacer una lectura social del territorio velando por no descuidar sus fundamentos ideacionales ni su dimensión identitaria (Debarbieux 2003).

En este artículo abordamos un estudio de caso que busca hacer dicha lectura, para explicar patrones de asentamiento en la sierra andina a la escala de formaciones socioterritoriales locales y discutir conceptos provenientes de fuentes etnohistóricas y etnográficas que podrían estar relacionadas con la territorialidad prehispánica.

Después de introducir las características generales del poblamiento prehispánico tardío de las regiones serranas de los Andes Centrales y de hacer una síntesis respecto de los principios vernáculos relacionados con la territorialidad prehispánica y las formaciones socioespaciales asociadas, este artículo expone un estudio de caso del poblamiento del valle del Apurímac en los Andes sur-peruanos. Se describen las características arquitectónicas y locacionales de los asentamientos prehispánicos tardíos identificados durante prospecciones en la sección de este valle ubicado al pie de la cordillera de Vilcabamba. Con el objetivo de desarrollar un enfoque multifactorial, los patrones de asentamiento son estudiados según la modelización exploratoria de interacciones socioespaciales, el análisis distribucional del poblamiento en relación con el escenario geoambiental y la caracterización de las cualidades paisajísticas de los asentamientos habitacionales. Los resultados de estos análisis son discutidos a la luz de datos etnohistóricos y analogías etnográficas, y son evaluados mediante un enfoque multiescalar.

Estos datos inéditos sobre el poblamiento prehispánico en el valle del Apurímac nos permitirán identificar la estructura socioespacial de las comunidades aldeanas del valle y examinar los vínculos de estas comunidades con formaciones socioterritoriales e identitarias más vastas. Asimismo, el enfoque multiescalar permitirá vislumbrar la complejidad geopolítica de la ocupación prehispánica de este espacio -donde confluyen varias áreas de influencias sociopolíticas y culturales-en particular durante el Horizonte Tardío (siglos XV-XVI) cuando 
el valle fue el escenario de una singular ocupación incaica relacionada con la implantación del dominio real de Choqek'iraw.

\section{Introducción al Poblamiento Prehispánico Tardío de las Regiones Serranas de los Andes Centrales}

Los estudios arqueológicos coinciden en señalar que el periodo Intermedio Tardío (siglos XI-XV) experimentó un crecimiento demográfico generalizado en los Andes Centrales (Covey 2008) con la ocupación de todas las facetas ecológicas del medio andino (Dollfus 1981). En las regiones serranas esta expansión del poblamiento se manifiesta por la multiplicación de los asentamientos $\mathrm{y}$ hacia las zonas de altura por encima de las tierras cultivables ${ }^{1}$.

La arquitectura habitacional de esta época es notablemente homogénea en las regiones serranas. Los asentamientos corresponden a conjuntos de construcciones en piedra, de planta mayormente circular pero también cuadrangular, según las regiones (Aldenderfer y Stanish 1993). Los más grandes se extienden hasta 70 ha y pueden reunir miles de estructuras aglutinadas, aunque estos grandes asentamientos son escasos y el grado de centralización de los patrones de asentamiento es muy variable según las regiones.

Los estudios regionales han sido a menudo realizados a escala de las antiguas provincias incas, las que corresponderían a formaciones territoriales étnicas preexistentes ${ }^{2}$ (Stanish 2001). Salvo excepciones -como la región del Mantaro donde se desarrolló una entidad política centralizada (D'Altroy y Hastorf 2001)-, los estudios de patrones de asentamiento evidencian la común fragmentación sociopolítica de los territorios del periodo Intermedio Tardío, incluso en regiones ocupadas por grandes grupos étnicos que supuestamente opusieron resistencia al imperialismo inca (Arkush 2009; Bauer y Kellett 2010; Schjellerup 2005). Para varios investigadores, esta aparente fragmentación territorial asociada a la frecuente presencia de asentamientos fortificados en cumbres es una evidencia de que el Intermedio Tardío fue un periodo de conflicto endémico, como lo relatan los mitos incas (Arkush y Stanish 2005).

El impacto de la integración de los territorios del periodo Intermedio Tardío al Tawantinsuyu durante el siglo XV es muy variable (Malpass 1993;
Stanish 2001). En ciertas regiones, la vida aldeana fuera de las infraestructuras imperiales no parece haber sufrido grandes cambios, mientras que en otras se produjeron modificaciones significativas en términos poblacionales y económicos ${ }^{3}$. En el caso de la cordillera suroriental donde se localiza nuestra zona de estudio, el reordenamiento territorial inca fue masivo, tanto en la zona nuclear de formación del Estado como en las provincias vecinas ${ }^{4}$. Pero a pesar de ello, y más allá de los drásticos cambios políticos, económicos y culturales ocurridos, las investigaciones tampoco evidencian un abandono masivo de los asentamientos habitacionales originarios del Intermedio Tardío. Pues en muchos casos estos pueblos siguieron ocupados a pesar de la reconfiguración de los sistemas y escenarios del poder (Acuto 2012). Asimismo, los patrones de asentamiento en la cordillera suroriental no experimentaron un cambio radical a pesar de los grandes cambios relacionados con el reordenamiento territorial inca, el cual consistió principalmente en la fundación de nuevos centros de poder con la implantación de colonias en zonas productivas (los fondos de valle, principalmente) y la creación de dominios reales (D'Altroy 2003), como es el caso de Choqek'iraw en el valle del Apurímac.

A la escala de la comunidad aldeana, son escasos los estudios sobre la arquitectura de los asentamientos habitacionales que permitan vislumbrar la organización de la vida social aldeana durante la época prehispánica tardía. En términos generales, las aglomeraciones comparten el carácter aglutinado y la homogeneidad constructiva de las estructuras habitacionales que las componen, así como la escasez de estructuras monumentales, las cuales se limitan en general a obras de carácter colectivo como los aterrazamientos y las fortificaciones relacionadas con el acondicionamiento y delimitación del espacio social. Los estudios con excavaciones a escala del grupo doméstico señalan un débil grado de estratificación social entre el colectivo de residentes (Bonnier 1997; Hastorf 2001; Lavallée y Julien 1973; Nash 2009). Pero si la morfología de estas aglomeraciones se relaciona a priori con escenarios sociales donde hubiera predominado el corporativismo de comunidades campesinas comprometidas en una economía agropastoril implicando altos niveles de cohesión social ${ }^{5}$, también existen muchas evidencias de diversas formas de segmentación del espacio social: barrios, patios, entre otras (Arkush 2009; DeMarrais 2001; Kosiba y Bauer 2012). Estas 
manifiestan sin duda la diversidad de la estructura social de las comunidades aldeanas en función de los tipos de asentamiento, de las regiones y de las conyunturas sociopolíticas. Por este motivo es necesario desarrollar mayores investigaciones acerca de estas formaciones sociales locales (la comunidad aldeana), en particular porque la caracterización de las comunidades a nivel local permite, desde una perspectiva bottom-up, desarrollar una lectura más social de los patrones de asentamientos regionales.

\section{Formaciones Socioterritoriales y Territorialidad en los Andes Prehispánicos Tardíos: Datos Etnohistóricos}

A pesar de los drásticos cambios en las estructuras sociopolíticas, económicas y culturales ocurridas desde la época colonial temprana (siglo XVI), se encuentran en la documentación etnohistórica descripciones de formaciones socioterritoriales prehispánicas y/o heredadas, a partir de las cuales es posible vislumbrar ciertos principios acerca de la territorialidad en los Andes prehispánicos (Moreno y Salomon 1991; Wachtel 1992 [1971]). Si bien estos documentos describen formaciones relacionadas con los contextos imperiales incas y coloniales españoles cuya perspectiva top-bottom no necesariamente traduce la realidad sociopolítica de las instituciones y territorios locales, constituyen sin embargo la única fuente de información emic disponible sobre la territorialidad prehispánica (fuera del ámbito de la cultura material). Destacamos las principales formaciones socioespaciales descritas en las crónicas y visitas para identificar conceptos respecto de la territorialidad prehispánica tardía, los cuales serán posteriormente discutidos en el contexto de nuestro estudio de caso en el valle del Apurímac.

La mayoría de la información disponible sobre la configuración socioespacial de los territorios prehispánicos se refiere a casos relacionados con el contexto imperial inca. El más conocido -el mismo núcleo del imperio en Cusco- formaba el estereotipo de un sistema especial centralizado con una configuración radial centrífuga estructurada por los famosos ceqes (Bauer 2000; Hyslop 1990). La dimensión territorial del modelo socioespacial cusqueño superaba ampliamente el mero reparto de las tierras y del agua, ya que este sistema formaba una representación geográfica del orden social, político y cosmológico, así como del calendario
(Zuidema 2010). Además, el sistema de ceqes evidencia el papel estructurante de los monumentos (wak'a) y hace hincapié al carácter práctico de la territorialidad inca, ya que movimientos rituales institucionalizados entre estos lugares sagrados constituían, combinado con la literatura oral, el principal medio de comunicación del orden territorial inca (Saintenoy 2013; Stanish y Bauer 2007; Van de Guchte 1999).

Otro modelo identificado con claridad, a distintas escalas, corresponde a una configuración socioespacial en franjas. Se trata en efecto de la estructura del macroterritorio aymara del Altiplano, como también del repartimiento de los territorios mitima del dominio cocalero inca de Cochabamba (Bouysse-Cassagne 1978; Wachtel 1980).

Es interesante que estos dos modelos socioespaciales de territorios tienen en común el ser representables sobre soportes textiles como el quipu (cuyas cuerdas con nudos conforman una estructura segmentada) y las túnicas y bolsos (cuyo degradado de colores en franjas es un concepto decorativo muy difundido). De hecho, esta analogía territorio/textil está ilustrada por la polisemia del término suyu, que se refiere por un lado a la noción de reparto social y territorial y por otro designa las vestimentas decoradas con franjas (Gonzáles Holguín 1989 [1608]). Es también interesante observar que la única mención de cartografía en las crónicas corresponde a una representación de ceqes sobre un soporte textil denominado, según Polo de Ondegardo, carpatira (Platt et al. 2006).

Respecto de las "provincias" incas (wamani en quechua), su envergadura y organización territorial eran muy variadas (Astuhuaman 2007; Parssinen 2003). Si bien los censos coloniales mencionan comunes casos de bi y cuatripartición sociopolítica cuya manifestación territorial ha sido vislumbrada por ciertos estudios de patrones de asentamiento (Bauer et al. 2010; Schjellerup 2005), tampoco existe evidencia respecto de configuraciones socioespaciales típicas. Pues es posible que no haya existido un estereotipo espacial de la provincia inca. En los archivos coloniales, estas aparecen principalmente como reparticiones de tributarios del sistema imperial. Pero muchos archivos las relacionan, a la vez, con identidades étnicas (teóricamente preexistente al reordenamiento inca). Además de los rasgos culturales de su población (idioma, vestimenta, entre otros), estas identidades regionales son frecuentemente definidas por referentes territoriales como lugares 
de origen (pacarina en quechua) y monumentos del paisaje (Albornoz en Duviols 1967).

Es bien conocido que visitas coloniales tempranas (previas al reordenamiento territorial toledano) evidencian la existencia de macroterritorios en forma de archipiélago extendidos a lo largo del escalonamiento ecológico andino. Estas formaciones se caracterizan por su fragmentación y discontinuidad espacial, por su organización en redes y por la existencia frecuente de zonas pluriétnicas a escala del valle y del pueblo ${ }^{6}$ (Murra 1996). Pero si bien evidencias arqueológicas vislumbran la antigüedad de tales redes verticales en tiempos prehispánicos, otras muestran que el origen de las formaciones descritas en los documentos del siglo XVI está estrechamente relacionado con coyunturas incaicas e incluso posteriores (Stanish et al. 1993; Van Buren et al. 1993).

En resumen, si bien las formaciones socioterritoriales descritas en la literatura etnohistórica corresponden a contextos políticos imperiales y coloniales, estas formaciones no son meros sistemas de repartición y administración de tributarios y tierras, ya que generalmente poseen una identidad territorial (basada tanto en referentes sociales como geosimbólicos). Es importante recalcar que las descripciones etnohistóricas, presentadas en una perspectiva top-bottom, hacen poco caso de las formaciones socioterritoriales locales. De hecho, estas últimas están descritas en términos de repartición de individuos y generalmente no en términos de repartición de tierras. Según estos documentos la autoridad de los jefes ${ }^{7}$ de estas comunidades se ejercía sobre la gente y no sobre las tierras, lo que cuestiona la existencia de la propiedad fundiaria en tiempos prehispánicos (Ramírez 2002). Asimismo, ha sido cuestionado que las formaciones sociales $-\operatorname{los}$ ayllus $^{8}$ - tuvieran bases territoriales, ya que se fundamentaban esencialmente por estructuras de parentesco biológico y/o ficticio y por otros referentes ideacionales no arraigados (Goldstein 2000). Sin embargo, dado el rol fundamental de los monumentos en la estructuración de las formaciones socioterritoriales descritas en las mismas fuentes etnohistóricas, resulta problemático este postulado teórico. Por ejemplo, el concepto de pacarina evidencia el carácter arraigado de las identidades sociales. Además, desde el punto de vista teórico, es necesario notar que una "comunidad imaginada" (sensu Isbell 2000) requiere prácticas colectivas e interacciones sociales para transmitir los referentes ideológicos que la fundamentan. Estas prácticas requieren lugares y escenarios, es por este motivo que las interacciones cotidianas entre individuos, como ocurre en el contexto de la comunidad aldeana, resultan importantes en los procesos de estructuración de la ideología colectiva mediante la práctica.

A continuación evaluaremos la cuestión de la territorialidad de las comunidades aldeanas en el valle del Apurímac, pero no solamente veremos los modelos y conceptos identificados en la literatura etnohistórica, sino también a partir de la literatura etnográfica respecto de épocas más recientes, cuya información ofrece un potencial analógico para la interpretación de los patrones de asentamientos prehispánicos (Politis 2002).

\section{El Valle Medio del Apurímac: Geografía y Etnohistoria}

El río Apurímac fluye en uno de los más profundos valles de los Andes Centrales. Su curso medio corresponde a la sección del valle situado al pie de la cordillera de Vilcabamba (Figura 1). En 20062007 esta región de cerca de $2.000 \mathrm{~km}^{2}$ fue objeto de prospecciones pedestres extensivas efectuadas en ambas laderas del valle. Se identificaron cerca de 200 sitios arqueológicos, de los cuales un centenar de asentamientos habitacionales corresponden a la época prehispánica tardía. La mayoría de los otros sitios presentan vestigios de acondicionamientos agropastoriles asociados al poblamiento prehispánico (Saintenoy 2008).

La región presenta una singular combinación de características que hacen de ella un contexto apropiado para el estudio de la estructura socioterritorial de las comunidades campesinas prehispánicas. Primero, porque se conserva una gran densidad de vestigios arqueológicos del poblamiento prehispánico. Segundo, porque este valle forma un contexto geoambiental especial con un excepcional espectro de recursos. El marcado escalonamiento ecológico y el acceso directo a las tierras bajas orientales permite el desarrollo de una economía agropastoril asociada al cultivo de productos de clima caliente (coca, algodón, ají, etc.), además de la explotación de una diversidad de recursos naturales: especies de plantas para usar como maderos, para uso medicinal y sicotrópico (p.ej., la vilca, Anadenanthera colubrina y el curu, Nicotiana tricholine) y minas (oro, plata, mercurio y sal gema). 


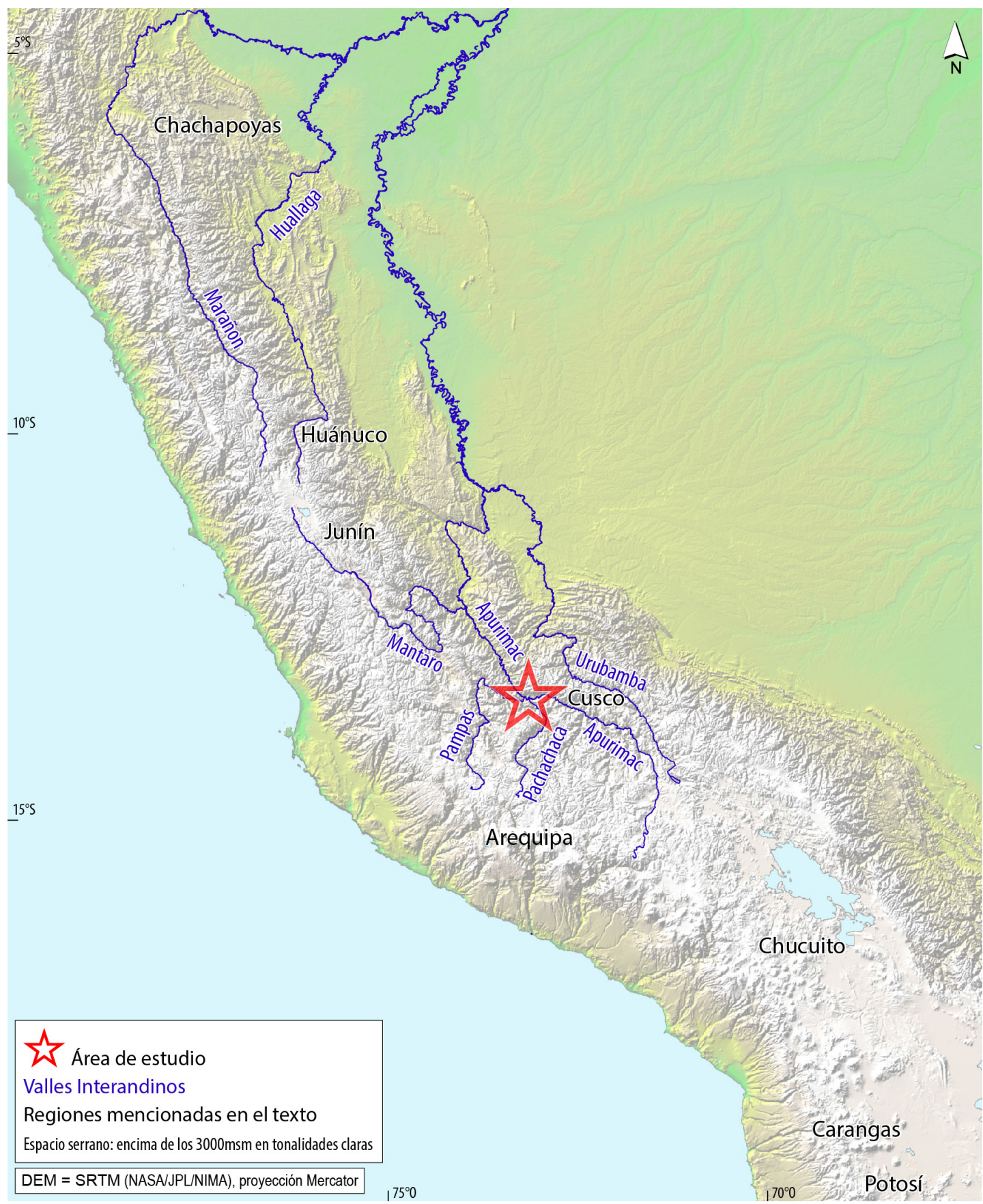

Figura 1. Localización del valle medio del Apurímac en los Andes Centrales.

Location of the Apurímac valley in the Central Andes.

Desde el punto de vista histórico, Vilcabamba es famosa por haber sido el último territorio inca durante las primeras décadas coloniales (Guillén Guillén 1984). Por lo mismo, las menciones acerca de la ocupación precolonial de la región son casi inexistentes en las crónicas. Durante la época inca, la región formó un espacio intermedio entre los dominios reales incas de la cordillera de Vilcabamba y los confines de las provincias chanca y quichua. Probablemente ocurrió lo mismo durante la época 
preinca cuando la cordillera de Vilcabamba estaba ocupada por conjuntos de comunidades aldeanas cuya afiliación étnica está invisibilizada en los textos por las referencias a la masiva ocupación inca (Duffait 2007; Saintenoy 2011).

Debido a la situación marginal de la región en la geopolítica colonial, los archivos administrativos coloniales son escasos y difíciles de tratar: aparentemente la región no fue objeto de visitas detalladas, mientras que los títulos de encomienda disponibles (la famosa Encomienda del Inca) esbozan la composición de territorios dispersos -heredados de los dominios reales incas-y difíciles de identificar por problemas de toponimia (Burga Díaz 2008; Duffait 2005; Hampe 1979; Hostnig et al. 2007; Julien 1998, 2002; Saintenoy 2011; Varón Gabai 1998).

\section{Arquitectura de los Asentamientos Habitacionales Prehispánicos del Valle del Apurímac}

Las prospecciones arqueológicas efectuadas en el valle identificaron los vestigios de 114 asentamientos habitacionales originarios de la época prehispánica tardía. Estos corresponden a aglomeraciones de estructuras habitacionales construidas con piedra (aunque en muchos sitios estas estructuras solo se identifican como simples depresiones en el suelo). La arquitectura de la estructura habitacional es homogénea en el conjunto de la región: es de planta circular y posee una sola abertura y un solo nivel. La calidad de la mampostería depende de las rocas disponibles en el lugar, aunque las estructuras mayores exhiben en general un aparejo más trabajado, como es el caso en otras regiones (DeMarrais 2001; Wernke 2006). Sin duda las disparidades constatadas en lo referente a sus dimensiones $\left(7-50 \mathrm{~m}^{2}\right)$ indican que no todas las estructuras circulares estaban destinadas al mismo tipo de actividades.

La dimensión de los asentamientos habitacionales es variable: algunos solo tienen una o dos estructuras aisladas pero las aglomeraciones mayores, que se extienden hasta 18 ha, reúnen cientos de estas. En los sectores mejor conservados la densidad de estructuras habitacionales por hectárea fluctúa entre 27 y 87 (lo que significa que el área techada representaba entre 5 y $16 \%$ de la superficie de la aglomeración). En algunos casos, las estructuras están agrupadas en un mismo nivel de terraza y a veces alrededor de un patio en el que se abren. En otras regiones donde esta configuración es recurrente, se ha planteado que estos conjuntos que conforman a veces pequeños dominios en el seno de las aglomeraciones eran habitados por una misma familia extendida, la cual constituía el grupo doméstico (Earle et al. 1987; Lavallée y Julien 1973). Pero en los asentamientos del valle del Apurímac son escasos este tipo de conjuntos habitacionales en torno a un patio común (conservados) y estos no presentan nunca más de cinco estructuras (Figura 2). En las aglomeraciones, redes de pasajes y rampas se entremeten entre las casas. Habitar en estas aglomeraciones donde las casas se encuentran frecuentemente aglutinadas, implicaba sin duda una sensación de vecindad. Así, la experiencia y el compartir cotidiano de un entorno visual, de un ambiente sonoro y de un universo olfativo comunes contribuía probablemente a la dimensión comunitaria de la vida social en el seno de las aglomeraciones (Acuto 2008).

Además de su extensión, los asentamientos habitacionales se distinguen por el grado de planificación del espacio construido. En efecto, varios sitios arqueológicos presentan vestigios de grandes obras de aterrazamiento emprendidas para estructurar el espacio aldeano (y en particular acondicionar áreas propicias para la circulación y las reuniones colectivas). En algunos casos, los asentamientos están estructurados en barrios. Por ejemplo, el mayor complejo residencial de la región, implantado sobre la cresta cimera de las alturas de Waskatay, donde los vestigios habitacionales prehispánicos se extienden sobre 18 ha, está fraccionado en cinco aglomeraciones que forman más barrios, algunos de ellos delimitados por muros y zanjas. Estos acondicionamientos que buscaban controlar el acceso a estos barrios, o por lo menos individualizarlos, constituyen un testimonio material de una segmentación del espacio social a una escala mayor que aquella de la segmentación en grupos domésticos materializada por los conjuntos con patio. Esta división evoca a los "ayllu barrios" documentados en etnografías de pueblos andinos (Abercrombie 2006 [1998]; Rivière 1983). Otro patrón de segmentación del espacio social se observa en los sitios de Toroyuq, Inkawasi y Quchapata, donde parejas de asentamientos -uno arriba, otro abajo- forman un patrón bipartito, manifestación clásica de la estructuración dual de las comunidades andinas y de sus arquitecturas (Moore 1995; Palomino Flores 1971).

Algunos asentamientos habitacionales presentan contextos funerarios. Sin embargo, las estructuras en 


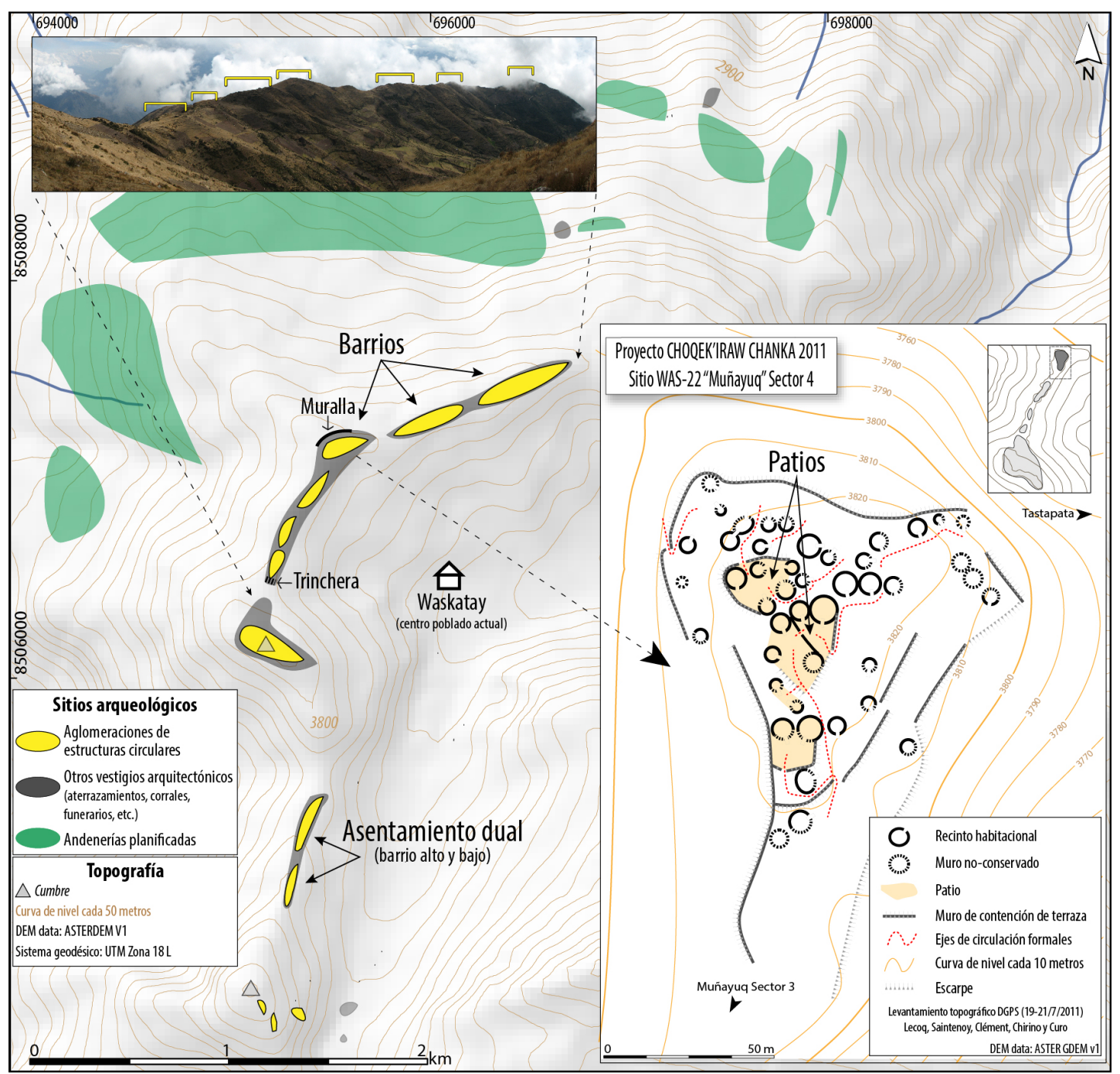

Figura 2. Planimetría del complejo habitacional de las alturas de Waskatay.

Multi-scalar organization of the residential complex of Waskatay region.

pozo empedrado típicas de la región para inhumar a los difuntos son difíciles de identificar a causa de la frondosa vegetación presente en la mayoría de los sitios. Por lo mismo, no se identificaron cementerios formales fuera de los asentamientos habitacionales, a excepción de contextos funerarios dispersos acondicionados al pie de afloramientos rocosos.

Dada la homogeneidad de la arquitectura doméstica, en ausencia de estructuras monumentales y considerando la difícil identificación de los contextos funerarios, son escasos los indicadores que permitan elaborar una tipología de los asentamientos habitacionales. Así, definimos una tipología basada en descriptores simples que son identificables en todos los sitios (independientemente de su estado de conservación) como la superficie del asentamiento y su grado de planificación (evidenciado por la presencia/ausencia de vestigios de obras de aterrazamiento del sitio y/o por la existencia de barrios).

\section{Características Locacionales de los Asentamientos Habitacionales Prehispánicos: Consideraciones Generales}

Siendo el valle medio del Apurímac uno de los cañones más profundos de los Andes, sus laderas pronunciadamente inclinadas entre 5.000 y $1.000 \mathrm{msm}$ 
dejan poco terreno adecuado para el asentamiento (Figura 3). La ocupación prehispánica se concentra sobre los contrafuertes de los cordones montañosos y sobre los espolones de sus laderas ${ }^{9}$ (Figura 4). Las crestas constituían el principal medio de vida, donde se encuentran los vestigios de los asentamientos habitacionales junto con los acondicionamientos del medio rural (aun frecuentemente reutilizados): redes viales, infraestructuras hidráulicas (canales y reservorios) y parcelas; aunque la mayoría de las zonas de cultivo se encuentran sobre sistemas de andenes que cubren las laderas de ambos lados de la cresta. Los asentamientos habitacionales que no se localizan en las crestas son generalmente más pequeños y menos estructurados. Se encuentran dispersos sobre las partes altas y bajas de las laderas, así como sobre los promontorios que dominan el fondo de valle.

En resumen, si bien el poblamiento prehispánico se extiende a todos los pisos del valle, la mayor parte de los asentamientos se encuentra en las alturas. Sobre las crestas, lomas y colinas formaron sitios

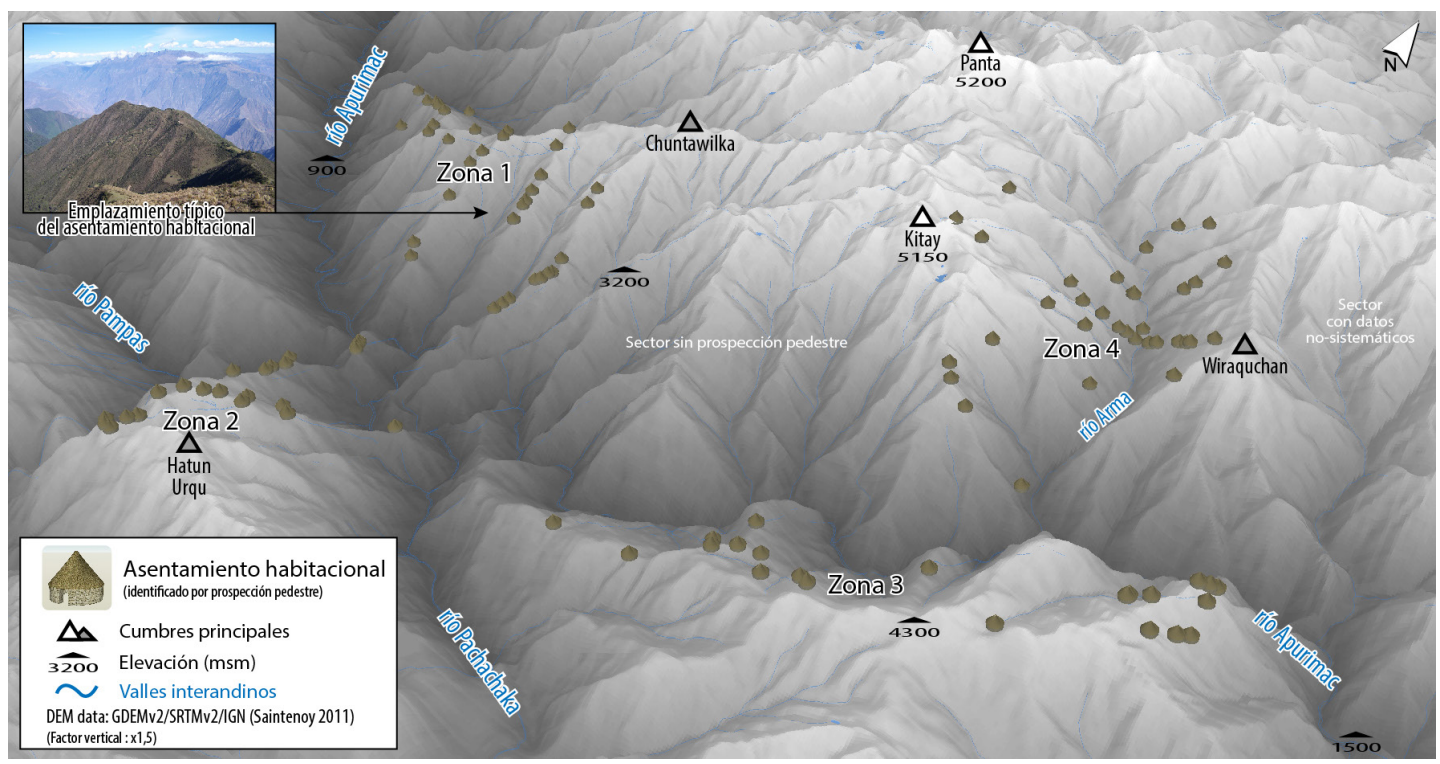

Figura 3. Implantación del poblamiento prehispánico tardío en el valle medio del Apurímac.

Late pre-Hispanic residential settlement pattern in the Apurímac valley.

Asentamiento
habitacional

Clasificación fisiográfica según Saintenoy (2011); índice de Prominencia topográfica según Weiss (2001) y Parcero y Fabrega (2006); DEM data: ASTER GDEMv2, SRTMv2, IGN (Saintenoy 2011)

Figura 4. Características locacionales de los asentamientos habitacionales en el valle medio del Apurímac Locational characteristics of late pre-Hispanic residential settlements in the Apurímac valley. 
preferenciales. ¿Con cuáles calidades de los sitios de altura se puede relacionar este patrón locacional tan marcado del poblamiento habitacional prehispánico tardío? Se podría evocar la mítica edad guerrera del periodo Intermedio Tardío para explicar una ubicación defensiva en potenciales refugios de difícil acceso. Pero es necesario notar que las crestas constituyen los terrenos más estables y más seguros en esta región de la cordillera oriental, cuya geodinámica con una intensa actividad sísmica y cuantiosas precipitaciones conjugadas con una frágil geología metamórfica. Las crestas garantizan también un número de horas de sol máximo, factor importante cuando se vive a $3.000 \mathrm{msm}$ en una zona tropical húmeda. Junto con estos potenciales factores políticos y geoambientales, se debe considerar la dimensión paisajística, ya que los sitios de altura ofrecen evidentemente un amplio panorama del paisaje serrano y, además, la implantación preferencial de lomas y colinas permite recíprocamente ver de lejos el pueblo.

\section{Interacción socioespacial y redes de asentamientos}

En los archivos de las visitas pretoledanas a las provincias de Chucuito y Huánuco (Diez de San Miguel et al. 1964; Murra 1972) nos informamos que era generalizado que un curaca estuviese a cargo de varios pueblos vecinos y que los miembros de un mismo ayllu habitasen en varios asentamientos. Estos datos etnohistóricos ponen en evidencia la existencia de redes de asentamientos, es decir, de conjuntos de asentamientos habitados por una misma comunidad y/o bajo la protección de una misma autoridad política. Por consiguiente, se plantea el problema de la identificación de estas redes de asentamientos a partir del registro arqueológico. Si bien el hecho que los censos disponibles -que evidencian relaciones de vecindad entre los pueblos bajo la autoridad de un mismo curaca- indican que la espacialidad no es ajena a la conformación de redes, falta sin embargo determinar las lógicas espaciales que las estructuran.

En ausencia de datos de censos para nuestra área de estudio comparables a los de Chucuito y Huánuco (por pueblo e incluso por casa), buscamos identificar la estructura territorial de las comunidades aldeanas prehispánicas según un proceso exploratorio de modelización socioespacial de parámetros arqueológicos y geográficos (Favory et al. 2012), buscamos evaluar las estructuras de interacción social potencial como estas están teóricamente ligadas a la espacialidad del poblamiento. Para ello desarrollamos aquí la hipótesis que la configuración de las redes de asentamientos se relaciona con la naturaleza de la interacción socioespacial entre los asentamientos habitacionales. Asimismo, siguiendo esta hipótesis espacialista, la intensidad de estas interacciones debería depender, en una medida socialmente significativa, de las relaciones de vecindad/distancia entre estos asentamientos porque estas predisponen, a escala local de lo cotidiano, los flujos de circulación y de intercambio de personas, bienes e ideas. Como el espacio es el producto de las prácticas sociales (y por tanto de interacciones entre individuos y colectivos sociales) es necesario ver en la estructura de estos flujos un factor significativo de la conformación territorial de las comunidades aldeanas (Lefebvre 2000 [1974]; Levy y Lussault 2003; Snead et al. 2009).

Para la modelización de las interacciones socioespaciales se aplicó un modelo gravitatorio simple que postula que la intensidad del flujo entre dos asentamientos es producto de la masa de estos asentamientos e inversamente proporcional a la distancia que los separa (Nuninger y Sanders 2006; Pumain y Saint-Julien 2001). En este caso, las masas están en función de las superficies de los asentamientos habitacionales ponderadas según la presencia/ausencia de vestigios de grandes obras de aterrazamiento que materializan el acondicionamiento del sitio y la planificación de la aglomeración. Respecto de las distancias, estas han sido calculadas según la simulación del camino óptimo considerando la pendiente como factor de fricción de la circulación pedestre $^{10}$ (Figura 5).

La modelización es de carácter exploratorio y se basa en criterios pragmáticos (o sea, en la distribución de los asentamientos habitacionales identificados en terreno). Además, es importante señalar que este tipo de análisis de interacción socioespacial se caracteriza por carecer de postulado de alguna centralidad (espacial) teórica, a diferencia de otros modelos de análisis espaciales comúnmente aplicados en arqueología. Por ejemplo, nuestra modelización no busca determinar áreas de influencia alrededor de los asentamientos: porque en el contexto andino prehispánico caracterizado por la discontinuidad de las influencias territoriales y la ausencia de propiedad fundiaria, un enfoque que pretenda atribuir porciones de espacio continuo a tal o cual asentamiento, como los desarrollados en otras áreas culturales (Bevan y 


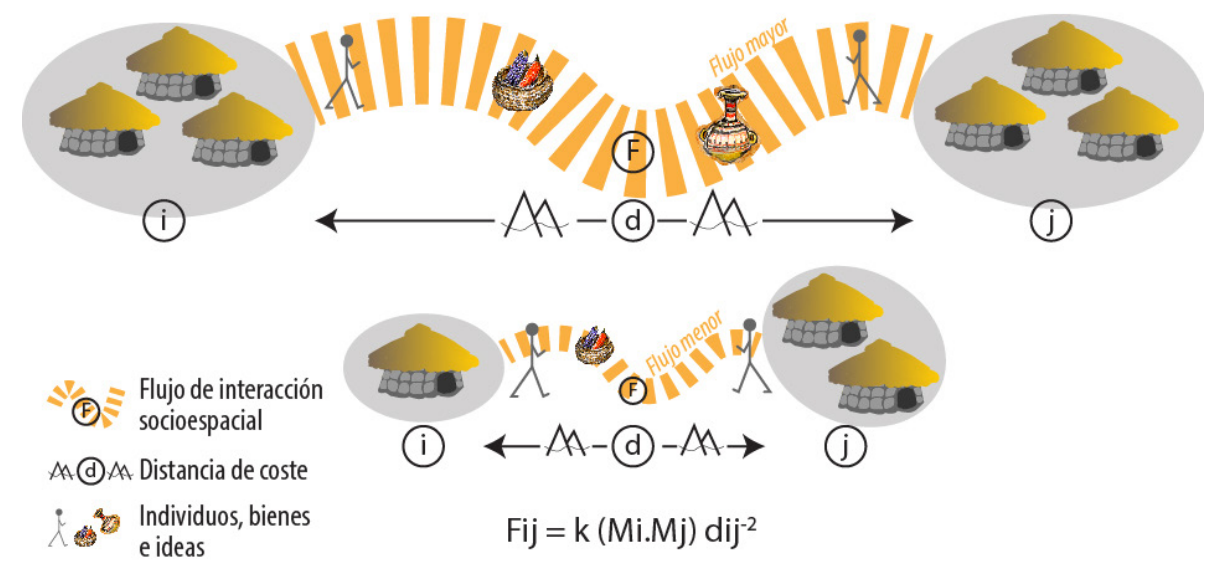

Figura 5. Modelo teórico de interacciones socioespaciales.

Theoretical model of socio-spatial interaction.

Wilson 2013; Ducke y Koefges 2008), podría ser erróneo (Harris 1997).

Además de evaluar las potenciales líneas de fuerza estructural de las redes de asentamientos, recurrir a la modelización permite comparar sobre bases cuantitativas la espacialidad del poblamiento de las distintas zonas de interés del área de estudio. El hecho que la sección del Apurímac localizada al pie de la cordillera de Vilcabamba se encuentre en la confluencia de tres de los mayores valles interandinos del sur de los Andes Centrales produce una zonificación geográfica muy marcada, la cual implica un tratamiento por zona del análisis socioespacial del poblamiento.

Los resultados brutos de la modelización (Figura 6) ponen en evidencia la heterogeneidad de las redes de asentamientos en la zona de estudio. En la zona 1, el patrón de asentamiento aparece segmentado en redes que corresponden a las principales unidades fisiográficas, al contrario de la zona 2 marcadamente centralizada. En la zona 3 se distingue un polo con redes anexas así como una red marginal en tierras altas. La zona 4 se caracteriza por su desigual patrón de asentamiento, centrado en torno al fondo del valle, y donde además destacan redes segmentadas análogas a las de la zona 1 sobre las laderas.

\section{Patrones de asentamiento y ecología cultural}

Las estructuras de las redes de asentamientos evidenciadas por la modelización de interacciones socioespaciales (Figura 6) corresponden a sistemas de ocupación del suelo bien documentados en la literatura etnográfica sobre la ecología cultural andina de los territorios campesinos de economía mixta agropastoril (Flores 1985; Yamamoto 1985). En el valle medio del Apurímac se distinguen varios tipos de redes que, en función de su localización y situación fisiográfica, se relacionarían con diversos tipos de economías campesinas. Las redes más comunes forman segmentos extendidos entre 1.500 y $4.000 \mathrm{msm}$ sobre los espolones laterales del valle. Su configuración podría relacionarse con una economía agropastoril con un vasto espectro de cultivos de tubérculos y cereales. En cuanto a las redes localizadas en los contrafuertes de los cordones montañosos (con núcleos habitacionales en torno a los 2.500-3.000 msm), estarían más orientadas a la producción de cereales en el piso quechua y a la explotación de productos de clima caliente en las zonas bajas a las cuales se tenía un acceso directo (Saintenoy 2011: para mayores detalles de los sistemas de asentamiento relacionados con economías agropastoriles).

El tipo de red más común en nuestra zona de estudio -las redes segmentadas extendidas sobre los espolones laterales del valle que se despliegan a través de varios pisos ecológicos (entre $1.500 \mathrm{y}$ $4.000 \mathrm{msm}$ )- forman un caso de especial interés. Pues esta configuración se inscribe en el paradigma de la verticalidad relacionado con el modelo etnohistórico del ideal ayllu autosubsistente (Murra 1983 [1978]). Este tipo de red es comparable con otros 


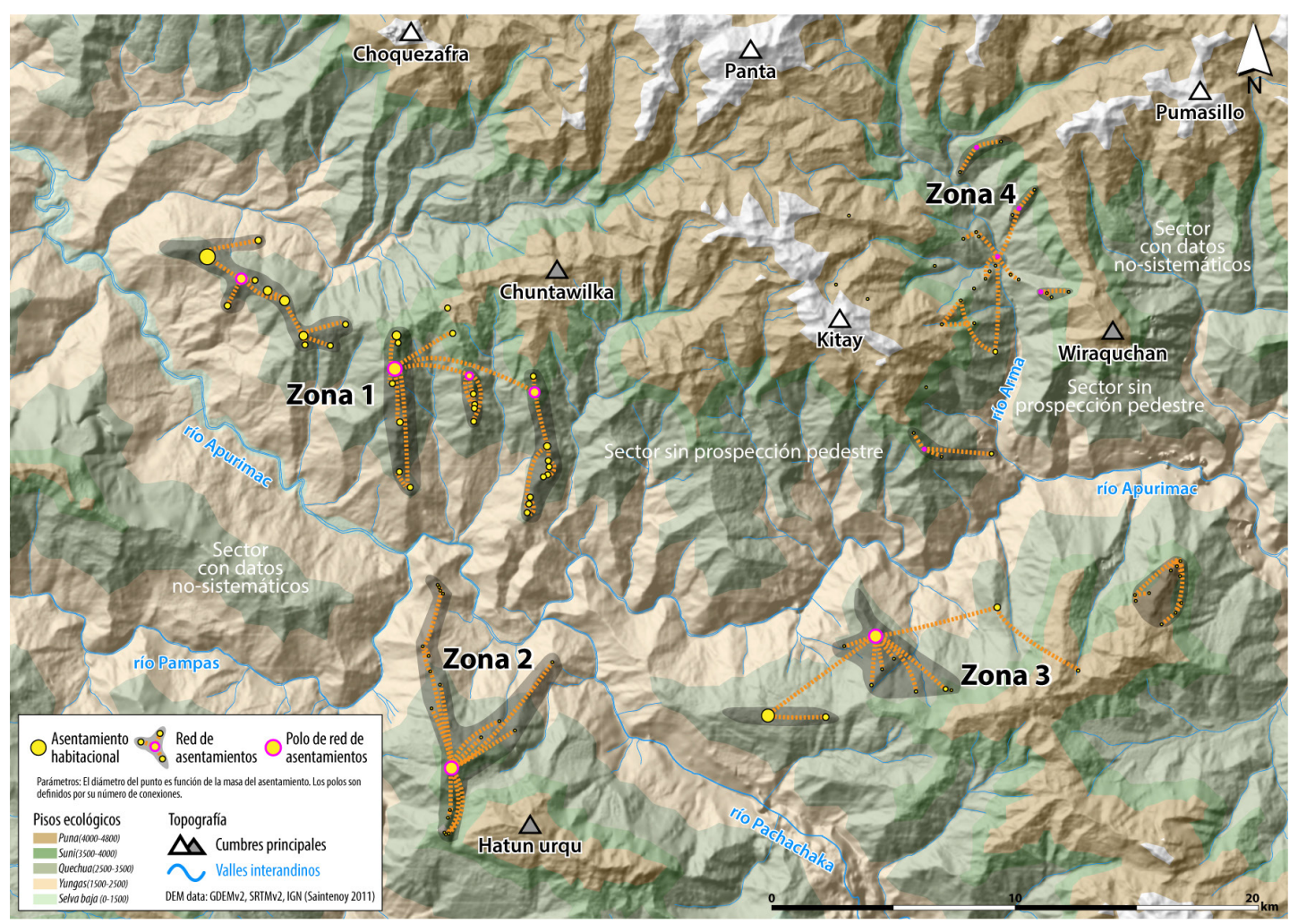

Figura 6. Redes de asentamientos del valle medio del Apurímac.

Settlement networks of the Apurímac valley.

territorios verticales como el caso etnohistórico de la formación archipielágica Chupaychu en Huánuco, así como los casos etnográficos de la comunidad indígena cusqueña Q'ero (Webster 2005 [1983]) y de la comunidad mestiza de Uchucmarca en el valle del Marañón (Brush 1977). Por ejemplo, el vasto territorio Q'ero se extiende entre $2.100 \mathrm{y}$ $4.300 \mathrm{msm}$ con un pueblo central ubicado a 3.400 msm y un fenómeno de plurirresidencia muy desarrollado. Pero existe una diferencia significativa, mientras las formaciones socioterritoriales Q'ero y Chupaychu requieren varios días de marcha para atravesarlas, los hipotéticos territorios verticales del valle medio del Apurímac se singularizarían por ser abarcables a escala de lo cotidiano, lo que constituye una envergadura más focalizada aún que la "microverticalidad" del territorio campesino de Uchucmarca, cuyos límites se encuentran a dos días del pueblo central.

En la práctica, los asentamientos habitacionales que formaban estas redes aldeanas del valle medio del Apurímac estaban separados por una media hora de caminata en promedio y articulados por un eje de circulación sobre la cresta, donde es también común encontrar vestigios de secciones de un canal el cual distribuía el agua captada en las zonas de altura al conjunto de los asentamientos y permitía al mismo tiempo irrigar los campos acondicionados a ambos lados de las laderas.

Respecto del potencial fenómeno de plurirresidencia, es ilustrativo mencionar aquí el caso de Gregorio Urbano, nuestro anfitrión durante los reconocimientos de terreno. Don Gregorio es agricultor y ganadero en la región de Inkawasi. Posee cuatro residencias dispersas entre 2.500 y $3.500 \mathrm{msm}$, las más alejadas están a una jornada de camino. La dinámica de plurirresidencia de don Gregorio depende principalmente del calendario agrícola, y se relaciona también con las actividades sociales de la comunidad y con la dinámica de conformación de su familia (Saintenoy 2011). No obstante el caso de don Gregorio sugiere una analogía interesante para 
pensar la dinámica social de las redes de asentamiento prehispánicas, lamentablemente los rastros de este fenómeno de multirresidencia parecen escapar al registro arqueológico.

Si bien las redes aldeanas del valle medio del Apurímac poseen una estructura socioespacial y geoambiental que tiende a individualizarlas como comunidades aldeanas desde el punto de vista territorial, por supuesto esto no descarta una dinámica social intensa e interdigitada entre los agentes de estas redes. Por ejemplo, esta segmentación espacial de las redes -que recuerda el modelo socioespacial en franjas de las fuentes etnohistóricas- podría inscribirse en una estructura de integración social piramidal multiescalar comparable a aquellas descritas en la etnografía de Platt (1978) de los Machas de la región de Potosí o en la de Rivière (1983) en el territorio Sabaya de Carangas. En este nivel interpretativo y teniendo en cuenta la naturaleza de los datos arqueológicos, cualquier hipótesis lleva un carácter especulativo, pues nos encontramos aquí confrontados a los límites de las promesas de la arqueología del asentamiento (Trigger 1967).

La literatura respecto del poblamiento prehispánico serrano en los Andes Centrales brinda pocos casos explícitos de tales redes de asentamientos a escala del territorio aldeano. Los reconocimientos de Deodat y Lecoq (2009), en el valle bajo del Pampas, evidencian patrones de asentamiento a lo largo de crestas similares a los del vecino valle medio del Apurímac. Pero los estudios regionales desarrollados en los cañones del Colca y de Cotahuasi (región de Arequipa)-que constituyen contextos comparables por su pronunciado escalonamiento vertical- no han documentado tal densidad ni una estructuración socioespacial vertical del poblamiento (Doutriaux 2002; Jennings y Yépez 2009; Wernke 2009). En cambio, encontramos indicios de potenciales redes análogas en los trabajos de Covey (2003:340) y Kendall (1984) en el valle del Vilcanota-Urubamba (Cusco). En cuanto al clásico estudio de Parsons (et al. 2000) de la región Tarama-Chinchaycocha (Junín), también hace énfasis, desde una perspectiva etnoarqueológica, en sistemas de asentamiento basados en la complementariedad socioeconómica, pero a una escala mayor a la ilustrada por el caso del valle medio del Apurímac, donde los medios agrícolas y pastoriles se encuentran cerca de ser fusionados.

\section{Particularidades locacionales de los asentamientos principales}

La mayoría de las redes de asentamientos del valle del Apurímac presentan un asentamiento principal. Se trata de un polo que, además de su posición nodal en la red, se distingue de los otros asentamientos por su mayor superficie y su mayor grado de acondicionamiento del sitio y de planificación de la aglomeración (Figura 6). En las redes de los espolones laterales el asentamiento principal ocupa siempre una posición intermedia cercana a $3.500 \mathrm{msm}$, en la interfaz de los medios agrícolas y pastoriles, lo que le otorga también una posición geosimbólica central (de tipo chawpi) en el seno del medio habitado (Earles y Silverblatt 1976). Esta evidencia de estructuración, no solo espacial sino también centralizada de las redes, constituye un argumento adicional en lo referente a su coherencia territorial.

La situación de estos asentamientos principales es análoga a las grandes aglomeraciones que constituyen frecuentemente la sede de comunidades aldeanas documentadas etnográficamente. Ateniéndonos a los ejemplos ya mencionados, la analogía con los casos de Q'ero y de Carangas -donde una gran aglomeración constituye un lugar central desde el punto de vista administrativo y ritual y en la cual casi todos los miembros de la comunidad tienen una residencia secundaria- podría explicar por qué los asentamientos principales del valle del Apurímac son los más poblados en número de estructuras habitacionales.

Además de su extensión y arquitectura, los asentamientos principales presentan una pronunciada singularidad locacional, poseen cualidades paisajísticas más desarrolladas que el promedio de los asentamientos (Figura 7), ya que se encuentran sobre lomas y cimas cuya prominencia topográfica forma hitos físicos identificables a lo lejos entre los paisajes serranos. Asimismo, los asentamientos principales fueron implantados en lugares que poseen cierta monumentalidad, la que otorgaba potencialmente a cada comunidad un lugar específico a la vista en el paisaje (según la asimilación del asentamiento a la geoforma del sitio). Por este motivo, este patrón locacional podría entonces haber desempeñado una función territorial. Efectivamente, en ausencia de representación cartográfica del territorio, el paisaje -el entorno natural y construido como es experimentado in visu 


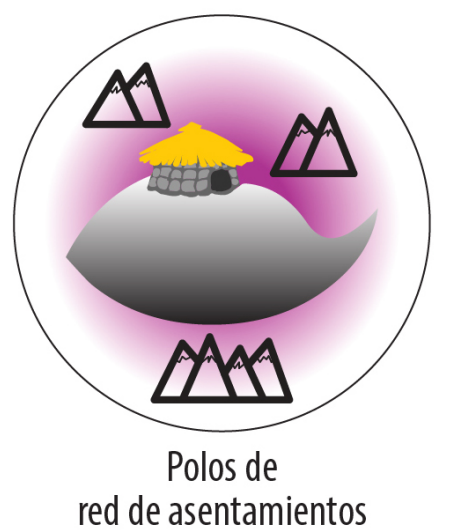

red de asentamientos

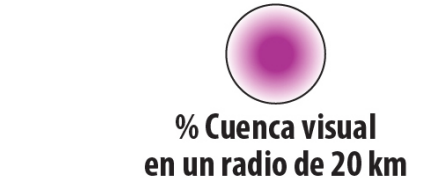

Polos Vs Todos

Global:

20\% - 11\%

Zona 1:

Zona 2:

Zona 3:

Zona 4:

$$
\begin{aligned}
& 20 \%-13 \% \\
& 36 \%-14 \% \\
& 16 \%-11 \% \\
& 07 \%-05 \%
\end{aligned}
$$

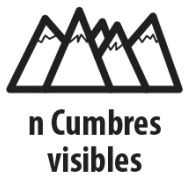

Polos Vs Todos

$08-05$

$03-01$

$15-07$

$08-08$

$06-05$
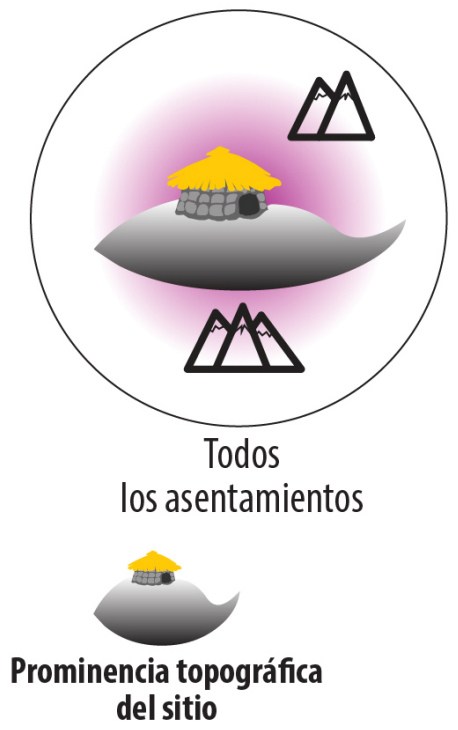

Polos Vs Todos

$1,8-1,0$

$1,7-1,3$

$2,2-1,1$

$2,1-1,0$

$1,0-0,5$

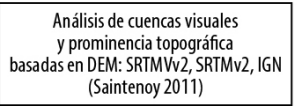

Figura 7. Cualidades paisajísticas de los asentamientos habitacionales. Landscape qualities of residential settlements.

y que está significado por los prismas culturales-era el principal referente territorial en muchas sociedades premodernas (Berque 1994; Thomas 2008).

\section{Territorialidad de las comunidades aldeanas: el concepto de llaqta}

Según la hipótesis que acabamos de exponer, la función territorial de los asentamientos principales del valle del Apurímac radicaba en su sistemática prominencia topográfica, la cual otorgaba a las comunidades aldeanas una identidad territorial tangible en el paisaje. Si ese fuera el caso, estos sitios constituían hitos territoriales que comunicaban la configuración socioespacial de los territorios de las comunidades locales. Así, esta configuración estaba definida por polos, centros -en este caso los asentamientos principales, en otros lugares quizás los pucaras-, y no por límites amojonados. Como escribe Bonnemaison (1981) acerca de los fundamentos del concepto de territorio, "la noción de frontera no es tan esencial como se quiere creer [...], porque un territorio es otra cosa que un espacio cerrado protegido por una frontera. En el fondo, es un núcleo, es decir, un centro mucho más que una barrera, y un tipo de relación afectiva y cultural a la tierra, antes de ser un reflejo de apropiación o de exclusión del extranjero". En el contexto andino prehispánico nada indica que los territorios fueran delimitados por deslindes lineales fijos construidos (Harris 1997). Los estudios etnohistóricos muestran que las influencias territoriales de las comunidades de origen prehispánico con frecuencia estaban interdigitadas y eran de manera constante renegociadas por el ritual y del conflicto (Molinié Fioravanti 1998; Ramírez 1985; Sanhueza 2008). Mientras estudios teóricos cuestionan la existencia de la propiedad fundiaria en tiempos prehispánicos (Testard 2005). Respecto de la demarcación territorial inca de las provincias, es de considerar que sus representaciones en las crónicas - por ejemplo, el amojonamiento ilustrado por Guamán Poma de Ayala (1615:355)- estén influenciadas por el nuevo orden territorial colonial español (Ramírez 2005). Desde el punto de vista 
arqueológico, los rastros de estructuras construidas de demarcación territorial son raros y se limitan generalmente a hitos cuyo origen cronológico y función exacta son difíciles de determinar, pero que probablemente más bien señalaban lugares centrales más que límites (Dean 2006). Respecto de las figuras naturales como las montañas y los ríos, estas constituían referencias y emblemas territoriales más que fronteras (Bouysse-Cassagne y Bouysse 1984; Martínez 1983; Reinhard 1983). Pasa lo mismo con edificios como las plataformas usnu y los mausoleos pucullu o chullpa que podían también constituir dispositivos y escenarios de construcción y negociación de la territorialidad (Bouysse-Cassagne y Chacama 2012; Isbell 1997; Meddens 2014). En todos los casos el conjunto de datos disponibles relativos a la configuración de los territorios prehispánicos no menciona una influencia territorial continua delimitada por un deslinde lineal construido. Como en muchas sociedades premodernas, la territorialidad estaba esencialmente encarnada, representada y comunicada por monumentos (Nieves Zedeño 2008). En el valle del Apurímac prehispánico los asentamientos habitacionales principales, por sus mismas características locacionales con especiales calidades paisajísticas, podrían haber desempeñado esta función territorial.

En la época colonial temprana, el término quechua llaqta designaba a las aldeas y más específicamente al asentamiento habitacional agrupado en los pueblos fundados por las autoridades coloniales (Gonzáles Holguín 1989 [1608]). Pero Taylor (1980) y Ramírez (2002) sugieren que el sentido prehispánico del término era otro. Tal como es utilizado en el manuscrito de Huarochirí del siglo XVI, llaqta designaba al conjunto del medio habitado: el asentamiento habitacional asociado a su entorno natural y acondicionado, así como el conjunto de los sujetos humanos y no humanos, alimentados todos por una misma energía vital -el camac-insuflado por la tierra y los ancestros. Encontramos representaciones análogas del territorio andino en las etnografías como en aquella del territorio Qollahuaya, el mismo que era asimilado a un cuerpo cuyos miembros y órganos estaban encarnados tanto por los asentamientos como por las principales figuras del medio natural (Bastien 1978). Por consiguiente, hay que pensar que los patrones de asentamiento tenían también una dimensión cosmológica y geosimbólica. Por ejemplo, el extirpador de idolatrías Arriaga (1968
[1621]) escribe a comienzos del siglo XVII que los indios viven en lugares altos para estar cerca de su lugar de origen y divinidad tutelar: motivo que, como lo observa Duffait (2012), invita no solo considerar criterios funcionalistas para explicar los patrones locacionales prehispánicos. En el caso del valle del Apurímac, el hecho que los asentamientos principales ofrezcan un panorama privilegiado sobre las altas cumbres de la cordillera de Vilcabamba (Figura 7), y que algunos de ellos alberguen en su seno monolitos wanka, podrían ser manifestaciones in visu y representaciones in situ de una arquitectura del paisaje relacionada con la faceta geosimbólica de la territorialidad prehispánica (Arguedas y Duviols 1966; Duviols 1967, 1979; Roger 1998).

Según esta lectura de los patrones de asentamiento a la luz de datos etnográficos, hay que considerar que las llaqtas del valle medio del Apurímac poseían fundamentos territoriales. Es más, este estudio invita a considerar que el compartir una representación común de su ecúmene era posiblemente uno de los factores esenciales de la cohesión social de la comunidad ${ }^{11}$. Pues, a escala de lo cotidiano, el territorio aldeano -la llaqtaformaba el escenario de las interacciones (tanto en discursos como en prácticas) que transmitían, reproducían y a veces reformulaban las ideas acerca de las identidades locales y de la eventual adhesión a una comunidad identitaria más amplia, más allá del colectivo de ayuda mutua campesina cotidiana (Wernke 2013).

\section{Las llaqtas del valle del Apurímac, el dominio inca de Choqek'iraw y las formaciones socioespaciales étnicas}

La documentación etnohistórica informa, desde una perspectiva top-bottom, que en tiempos incas el valle medio del Apurímac no formaba un territorio homogéneo, sino un espacio intermedio situado en los confines de las provincias de los Chancas y de los Quichuas y de los dominios reales de Vilcabamba. Estos límites correspondían más o menos a la confluencia de los valles interandinos: Apurímac, Pachachaka y el Pampas (Figura 8). Sin embargo, las fuentes son escasas y entregan escasos detalles sobre la ocupación de un espacio intermedio y a sus dinámicas geopolíticas. Entregamos, a continuación, un panorama de la ocupación del valle en tiempos prehispánicos tardíos, como lo 


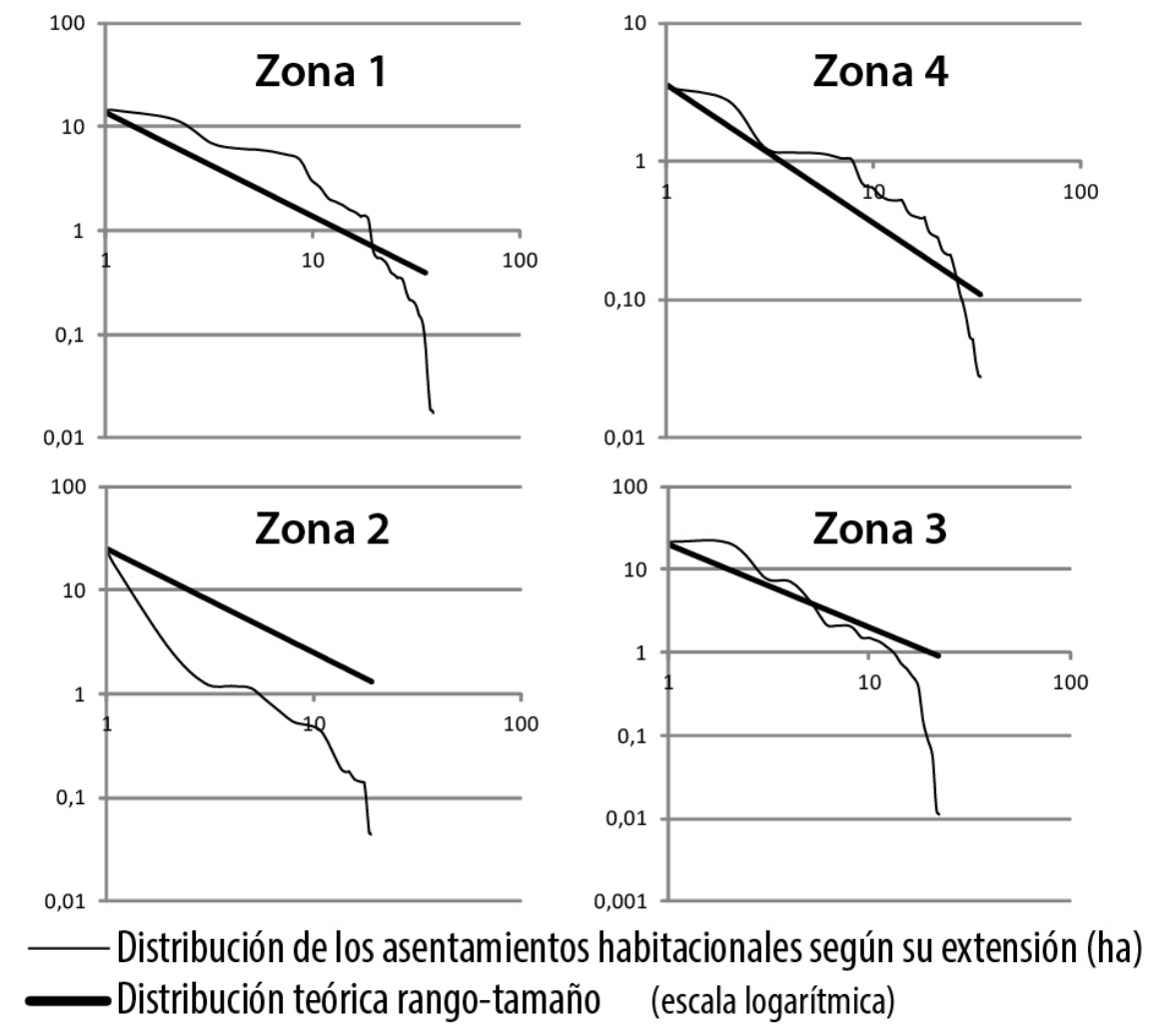

Figura 8. Ocupación prehispánica tardía del valle medio del Apurímac.

Late pre-Hispanic occupation of the Apurímac valley.

permite vislumbrar la confrontación de los datos arqueológicos y etnohistóricos.

En términos generales, los resultados de los reconocimientos arqueológicos evidencian que a pesar de formar uno de los más profundos cañones de los Andes, el valle medio del Apurímac fue densamente poblado. Lo esencial del poblamiento lo constituyen las comunidades aldeanas de probable origen preinca. Pero se evidencia también una marcada ocupación inca correspondiendo al dominio real de Choqek'iraw (Lecoq y Saintenoy 2014; Saintenoy 2011).

El dominio inca se caracteriza por formar un conjunto de asentamientos y acondicionamientos concentrados en un radio de un día de caminata alrededor del palacio de Choqek'iraw. Este conjunto de sitios exhibe una diversidad de arquitecturas ceremoniales, agrícolas, hidráulicas, viales y mineras; pero es notable la escasez de arquitectura habitacional con viviendas circulares alrededor de Choqek'iraw ${ }^{13}$. Es probable que el dominio real se extendiera a la margen izquierda del valle del Apurímac, porque además de presentar sitios con arquitectura inca, las regiones de Quinualla y Urcon carecen también de vestigios de gran asentamiento habitacional, así como porque catastros coloniales tempranos mencionan la presencia de bosques y cocales del Inca y de tierras perteneciendo a la encomienda del Inca (Burga Díaz 2008; Duffait 2005). La ocupación de dichas tierras podría relacionarse con el ordenamiento territorial inca de las laderas bajas del valle del Apurímac, donde habrían sido asentados colonos originarios de la costa y de la vecina montaña amazónica para su explotación agrícola (Garcilaso de la Vega 1976 [1609]; Renard-Casevitz et al. 1986).

Fuera del dominio real de Choqek'iraw, los vestigios de cultura material inca río abajo son relativamente escasos, limitándose a arquitecturas intrusivas y fragmentos de cerámica inca en asentamientos habitacionales ${ }^{13}$. Pero estos escasos edificios incas se encuentran en importantes 
asentamientos principales de las comunidades aldeanas, los mismos que forman los centros de los territorios aldeanos. Aunque la impronta de material inca pareciera escasa en el valle (aparte del dominio de Choqek'iraw), las llaqtas fueron incorporadas al sistema imperial mediante la implantación de edificios incas en los principales centros de poder locales, mientras la implantación de mitima en el fondo de valle implicó sin duda complejas negociaciones políticas y territoriales a nivel local (Saintenoy 2011).

Respecto de la situación socioterritorial de las comunidades aldeanas, se confrontan a continuación tres líneas de evidencias: los datos etnohistóricos, la modelización rango-tamaño de los patrones de asentamiento a escala microrregional y los datos referentes a la cultura material.

Los datos etnohistóricos estipulan que la región se encontraba al cruce de distintas formaciones socioterritoriales. El valle del Pachachaka se encontraba en la interfaz de las provincias chanca y quichua (Duviols 1967). En el valle del Apurímac, la región de Waskatay podría haber conformado la fachada septentrional de la región chance, ya que varias localidades de las inmediaciones son mencionadas en el título de encomienda chanca de Maldonado, pero no Waskatay, tal vez por una cuestión de toponimia (Julien 2002). En cuanto al macizo del valle del Apurímac situado más allá de Pachachaka, según Garcilaso de la Vega (1976 [1609]) esta región -que habría estado integrada al imperio inca antes de la famosa guerra contra los Chancas- era habitada por las naciones de Tacmara y Quinualla (que siguen siendo los topónimos de las dos principales comunidades actuales). Los habitantes de Tacmara servían al tampu de Abancay (Vaca de Castro 1989 [1543]). Respecto de la cordillera de Vilcabamba, las fuentes escritas se limitan a describir la resistencia inca y solo mencionan parcialmente la composición de los dominios reales, tanto así que es casi nula la información sobre la ocupación autóctona de origen preinca (Guillén Guillén 1980; Varón Gabai 1998). Por último, la presencia de una colonia de explotación de sal y la mención de prácticas caravaneras para el trueque de ganado por coca muestran que las llaqtas del valle del Apurímac pertenecían a redes de complementariedad ecológica a escala del departamento de Apurímac, lo que deja suponer que estas habrían podido estar afiliadas a formaciones socioterritoriales más vastas durante la época prehispánica.
La lectura sociopolítica de los territorios según la modelización rango-tamaño de los patrones de asentamiento concuerda bien con el esbozo etnohistórico referente a la geopolítica del valle del Apurímac (Figura 9). La zona 2 presenta un poblamiento altamente centralizado con el gran asentamiento habitacional de las alturas de Waskatay a la cabeza. El poblamiento de la zona 3 es descentralizado, a semejanza de los territorios de las naciones de Tacmara y Quinualla de las fuentes escritas. Respecto de Vilcabamba (zonas 1 y 4), su poblamiento segmentado corresponde, desde el punto de vista de la modelización rango-tamaño, a curvas convexas que representan territorios donde cohabitarían varias entidades jerarquizadas de mediano tamaño. Finalmente, es interesante notar que el grado de centralización de los territorios parece ir a la par con la importancia de la planificación del acondicionamiento agrícola: por ejemplo, la región de Waskatay presenta vastos sistemas de aterrazamientos agrícolas de diseño arquitectónico homogéneo, mientras estos son escasos en torno a las redes de asentamientos en franja de Vilcabamba.

Del punto de vista de la cultura material, las comunidades aldeanas del valle del Apurímac son aparentemente homogéneas, pues además de compartir la arquitectura habitacional los sitios exhiben una cerámica correspondiendo principalmente a un mismo estilo tecnológico ${ }^{14}$. Sin embargo, ciertos datos se relacionan también con el complejo panorama geopolítico esbozado por las fuentes etnohistóricas como por los patrones de asentamiento. Primero, cabe observar que si bien la arquitectura doméstica es homogénea en el conjunto de la región, en otros lugares de los Andes las distinciones étnicas/culturales no se manifiestan siempre en la arquitectura: es el caso por ejemplo de los asentamientos multiétnicos Chupaychu (Grosboll 1993). Respecto de la cerámica, si bien la mayoría de la muestra compuesta por una recolección sistemática en el conjunto del valle corresponde al mismo estilo tecnológico, el estudio de la materia prima revela una producción independiente a ambos lados del valle (Saintenoy 2011). Finalmente, dos conjuntos estilísticos de procedencia muy localizada constituyen serios indicios para las hipótesis planteadas (Figura 9), por un lado, el gran asentamiento residencial de las alturas de Waskatay exhibe los únicos fragmentos de cerámica polícroma no inca de toda la región, 


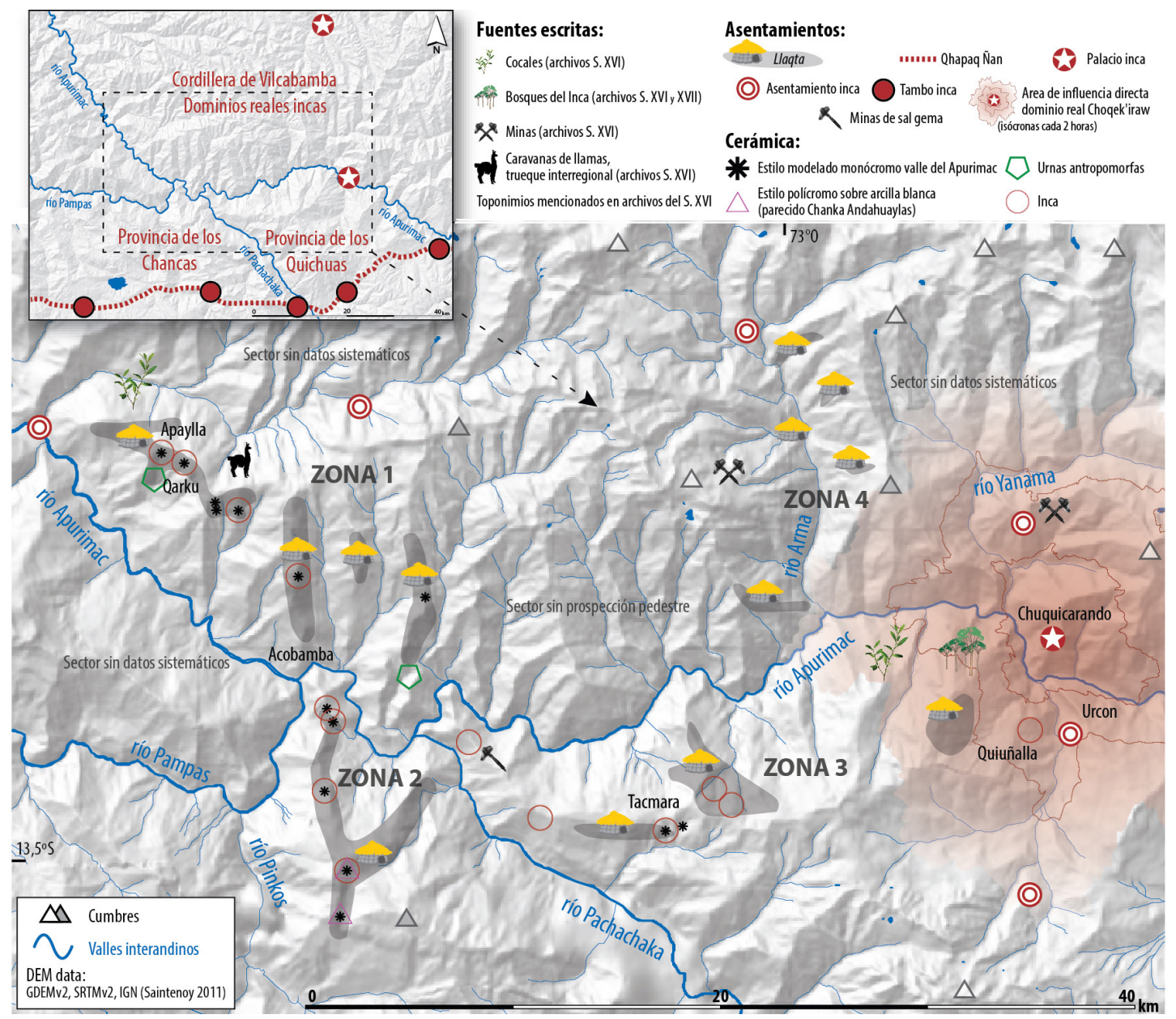

Figura 9. Modelización rango-tamaño de los patrones de asentamiento.

Rank-size graph for settlement patterns.

cuyas decoraciones evocan el estilo chanca de la región de Andahuaylas (Bauer et al. 2010). Y, por otro lado, urnas antropomorfas identificadas en las laderas bajas de la región de Inkawasi -que se inscribirían en una tradición funeraria amazónicamaterializan las colonias de grupos originarios de la montaña asentados en los valles interandinos (Renard-Casevitz et al. 1986).

El conjunto de datos que presentamos en un diálogo pluridisciplinario respecto del poblamiento prehispánico tardío del valle medio del Apurímac ilustra la complejidad y el carácter multiescalar e interdigitado de las formaciones socioterritoriales prehispánicas. El estudio evidencia también que lejos de formar fronteras fijas, los espacios intermedios de las culturas territoriales premodernas constituían medios de intensas y dinámicas interacciones socioculturales regidas no solo por las formaciones estatales, sino articuladas a la vez por la agencia de los grupos locales (McCarthy 2008).

\section{Conclusión}

El trabajo que acabamos de presentar acerca de las llaqtas del valle del Apurímac evidencia que la identificación del ayllu basada en los vestigios arqueológicos de su territorio es una tarea audaz. Por un lado, porque como escribe Testard (2005) para concluir su ensayo de clasificación de las formas de sociedad, no es "tan fácil remontar de un plano de aldea a las estructuras sociales". Y por otro lado, porque las comunidades se forman y se reformulan en el discurso sobre bases ideacionales que no siempre encuentran eco en la materialidad 
del archivo arqueológico. Sin embargo, como lo observa Isbell (2000), "mientras la comunidad imaginada está socialmente producida en discursos, estos no son independientes de los lugares, especialmente en la antigüedad". En efecto, vínculos fundamentales suelen unir a una formación social con su medio de vida, no solo porque este último es un hábitat -teatro de la subsistencia, de la vida social y de su reproducción-, sino también porque la tierra (cercana o lejana) constituye un referente fundamental de orden cultural e identitario del colectivo que la reivindica (Godelier 2007). Así, la territorialidad produce y se manifiesta a través de estructuras socioespaciales. Estas son las estructuras que este estudio pretendió identificar a escala de la comunidad aldeana serrana en el contexto de los Andes prehispánicos tardíos. Para lograrlo se desarrolló una metodología que combinó perspectivas de dos posiciones teóricas, a veces opuestas en la tradición de las ciencias sociales como la geografía espacial y la geografía cultural. De esta manera, la coherencia de la modelización propuesta de las redes de asentamientos aldeanas, la llaqta, es puesta en evidencia tanto por su estructura geoespacial y ecológica (en función de las condiciones geoambientales y de las prácticas campesinas andinas) como por su jerarquía sociopolítica y su potencial geosimbólico (en el contexto cosmológico y de los sistemas de representación paisajísticos como están documentados por la etnohistoria y la etnografía).

Desde el punto de vista metodológico, este trabajo aprehendió los patrones de asentamiento a escala de la llaqta (la red de asentamientos aldeana), escasamente tratada en los Andes Centrales. Adoptó una perspectiva bottom-up para hacer una lectura social (de carácter etnoarqueológico) de los territorios, y de esta manera refinar las clásicas lecturas sociopolíticas basadas en la modelización jerárquica del poblamiento a escala regional (Brun y Michelet 2012; Johnson 1977; Marcus 2000). A propósito, este estudio no enfocó una región con características geoambientales y/o territoriales bien delimitadas, al contrario, se interesa por una región de confluencia, escenario de complejas interacciones territoriales multiescalares. Asimismo, la iniciativa permite librarse en parte de la visión colonial relativa a los órdenes territoriales incas y españoles, la misma que discuten la mayoría de los estudios regionales respecto de la época prehispánica tardía (Stanish 2001). En particular, esta perspectiva ofrece el potencial de captar la agencia geopolítica de las llaqtas en la conformación de los territorios étnicos y en consecuencia de superar la visión esencialista de la provincia inca como es frecuentemente presentada en las crónicas.

Agradecimientos: Las investigaciones en terreno fueron financiadas por el Instituto Francés de Estudios Andinos (UMIFRE 17 CNRS MAE). Se realizaron con la autorización del Instituto Nacional de Cultura del Perú y contaron con la codirección de Homar Gallegos, Patrice Lecoq, Dominique Guillaud, Pierre Usselman y Mariusz Ziólkowski evaluaron la tesis de doctorado de la cual proviene la mayor parte de los datos expuestos en este artículo de síntesis: sus comentarios contribuyeron plenamente en su puesta en valor. El desarrollo de mis investigaciones acerca de la territorialidad en los Andes prehispánicos, financiadas por el FONDECYT 11121665, permitió madurar aspectos teóricos. Carole Dudognon desarrolló el script para el cálculo de los flujos de interacciones espaciales. Sandra Recarte y Daniella Jofré realizaron las traducciones al castellano y al inglés del manuscrito original. Las acertadas observaciones de los cinco evaluadores anónimos del manuscrito permitieron refinar significativamente la exposición de los datos.

\section{Referencias Citadas}

Abercrombie, T. 2006 [1998]. Caminos de la Memoria y del Poder. Etnografía e Historia en una Comunidad Andina. Institut Français d'Études Andines, IEB, ASDI, La Paz.

Acuto, F.A. 2008. Materialidad, espacialidad y vida social: Reinterpretando el Periodo Prehispánico Tardío de los Andes del Sur. En Sed non Satita II. Acercamientos Sociales en la Arqueología Latinoamericana, editado por F.A. Acuto y A. Zarankin, pp. 159-193. Serie Colección Contextos humanos.
Encuentro Grupo Editor, Universidad Nacional de Catamarca, Universidad de los Andes, Córdoba.

Acuto, F.A. 2012. Landscapes of inequality, spectacle and control: Inka social order in provincial contexts. Revista Chilena de Antropología 25:9-64.

Aldenderfer, M. y C. Stanish 1993. Domestic architecture, household archaeology and the past in the south-central Andes. En Domestic Architecture, Ethnicity, and Complementarity in 
the South Central Andes, editado por M. Aldenderfer, pp. 1-12. University of Iowa Press, Iowa City.

Allen, C. 2008. La Coca Sabe. Coca e Identidad Cultural en una Comunidad Andina. Centro Bartolomé de las Casas, Cuzco.

Arguedas, J.M. y P. Duviols (eds.) 1966. Dioses y Hombres de Huarochiri. Edición bilingüe. Narración Quechua Recogida por Francisco de Ávila [1598?]. Serie Fuentes e investigaciones para la historia del Perú: Textos críticos 1. Museo Nacional de Historia, Instituto de Estudios Peruanos, Lima.

Arkush, E. 2009. Pukaras de los Collas: Guerra y poder regional en la cuenca norte del Titicaca durante el Periodo Intermedio Tardío. ANDES: Boletín de la misión arqueológica andina Universidad de Varsovia 7:463-480. Arqueología del área centro sur andina: Actas del simposio internacional 30 de junio - 2 de Julio de 2005, Arequipa.

Arkush, E. y C. Stanish 2005. Interpreting conflict in the ancient Andes. Current Anthropology 46:3-28.

Arriaga, P.J. de 1968 [1621]. Extirpación de la Idolatría del Piru: Crónicas Peruanas de Interés Indígena. Serie Biblioteca de Autores Españoles 209. Ediciones Atlas, Madrid.

Astuhuaman, C. 2007. El concepto de provincia inca. Arqueología y Sociedad 17:273-292.

Barth, F. (ed.) 1998 [1969]. Ethnic Group and Boundaries: The Social Organization of Culture Difference. Waveland Press, Long Grove.

Bastien, J. 1978. Moutain/body metaphor in the Andes. Bulletin de l'Institut Français d'Etudes Andines 7:87-103.

Bauer, B.S. 2000 [1998]. El Espacio Sagrado de los Incas, el Sistema de Ceques del Cuzco. Serie Archivos de Historia Andina 33. Centro de estudios regionales andinos "Bartolomé de Las Casas", Cuzco.

Bauer, B.S. y A. Covey 2002. Processes of state formation in the Inca heartland (Cuzco, Perú). American Anthropologist 104:846-864.

Bauer, B.S. y L.C. Kellett 2010. Cultural transformations of the Chanka homeland (Andahuaylas, Peru) during the Late Intermediate Period (A.D. 1000-1400). Latin American Antiquity 21:87-111.

Bauer, B.S., L.C. Kellett, M. Aráoz, S. Hyland y C. Socualaya 2010. The Chanka: Archaeological Research in Andahuaylas (Apurímac), Peru. Serie Monograph Cotsen Institute of Archaeology 68. Cotsen Institute of Archaeology Press, Los Angeles.

Berque, A. 1994. Paysage, milieu, histoire. En Cinq Propositions pour une Théorie du Paysage, editado por A. Berque, pp. 11-30. Champs Vallon, Seyssel.

Bevan, A. y A. Wilson 2013. Models of settlement hierarchy based on partial evidence. Journal of Archaeological Science 40:2415-2427.

Bonnemaison, J. 1981. Voyage autour du territoire. Espace Géographique 10:249-262.

Bonnier, E. 1997. Morfología del espacio aldeano y su expresión cultural. En Prehispanic Architecture and Civilization in the
Andes, editado por E. Bonnier y H. Bischof, pp. 28-41. Serie Arqueológica Peruana 2. Sociedad Arqueológica PeruanoAlemana, Reiss- Museum Mannheim, Mannheim.

Bouysse-Cassagne, T. 1975. Pertenencia étnica, status económico y lenguas en Charcas a fines del siglo XVI. En Tasa de la Visita General de Francisco de Toledo, editado por D.N. Cook. UNMSM, Lima.

Bouysse-Cassagne, T. 1978. L'espace aymara: urco et uma. Annales Economies Sociétés Civilisations: Numéro Spécial Anthropologie Historique des Sociétés Andines 5-6:1057-1080.

Bouysse-Cassagne, T. y P. Bouysse 1984. Volcan indien, volcan chrétien. À propos de l'éruption du Huaynaputina en l'an 1600 (Pérou méridional). Journal de la Société des Américanistes 70:43-68.

Bouysse-Cassagne, T. y J. Chacama 2012. Partición colonial del territorio, cultos funerarios y memoria ancestral en Carangas y Precordillera de Arica (Siglos XVI-XVII). Chungara Revista de Antropología Chilena 44:669-689.

Brun, P. y D. Michelet 2012. Organisation politique et archéologie. En L'Archéologie à Découvert, editado por S. De Beaune y H.-P. Francfort, pp. 193-201. CNRS editions, Paris.

Brush, S.B. 1977. Mountain, Field, and Family: The Economy and Human Ecology of an Andean Valley. University of Pennsylvania Press, Philadelphia.

Burga Díaz, M. 2008. Choquequirao: Símbolo de la Resistencia Andina (Historia, Antropología y Lingüística). Universidad Nacional Mayor de San Marcos, Fondo Contravalor Perú-Francia, Institut Français d'Études Andines, Lima.

Chepstow-Lusty, A.J., M.R. Frogley, B.S. Bauer, M.B. Bush y A.T. Herreras 2003. A late Holocene record of arid events from the Cuzco region, Peru. Journal of Quaternary Science 18:491-502.

Cieza de León, P.d. 1946 [1553]. Crónica del Perú. Editorial Nueva España, México D.F.

Cook, D.N. 1975. Tasa de la Visita General de Francisco de Toledo. UNMSM, Lima.

Covey, A.R. 2003. A processual study of Inka State formation. Journal of Anthropological Archaeology 22:333-357.

Covey, A.R. 2008. Multiregional perspectives on the archaeology of the Andes during the Late Intermediate Period. Journal of Archaeological Research 16:287-338.

D'Altroy, T.N. y C.A. Hastorf (eds.) 2001. Empire and Domestic Economy. Serie Interdisciplinary contributions to archaeology. Kluwer Academic, New York.

Dean, C. 2006. Rethinking Apacheta. Nawpa Pacha 28:93-108.

Debarbieux, B. 2003. Territoire. En Dictionnaire de la Géographie et de l'Espace des Sociétés, editado por J. Levy y M. Lussault, pp. 910-912. Belin, Paris.

DeMarrais, E. 2001. The architecture and organization of Xauxa settlements. En Empire and Domestic Economy, editado por T.N. D’Altroy y C.A. Hastorf, pp. 115-154. Kluwer Academic Press, New York, Boston, Dordrecht, London, Moscow.

Deodat, L. y P. Lecoq 2009. Images satellitaires et prospection archéologique. Un cas d'école dans les Andes péruviennes Les Nouvelles de l'Archéologie 117:54-64. 
Di Méo, G. y P. Buléon 2005. L’Espace Social. Lecture Géographique des Sociétés. Armand Colin, Paris.

Diez de San Miguel, G., W. Espinoza Soriano, P. Gutiérrez Flores y J.V. Murra 1964. Visita hecha a la Provincia de Chucuito por Garci Diez de San Miguel en el año 1567. Versión Paleográfica de la Visita y una Biografía del Visitador por Waldemar Espinoza Soriano. Padrón de los Mil Indios Ricos de la Provincia de Chucuito en el año 1574. Serie Documentos regionales para la etnología y etnohistoria andinas, $\mathrm{t}$ 1. Casa de la Cultura del Perú, Lima.

Dollfus, O. 1981. El Reto del Espacio Andino. Serie Perú problema 20. Instituto de Estudios Peruanos, Lima.

Doutriaux, M. 2002. Relaciones étnicas y económicas de poder: la conquista incaica en el valle de Colca, Arequipa. Boletín de Arqueología PUCP 6:411-432.

Ducke, B. y P.C. Koefges 2008. From points to areas: constructing territories from archaeological site patterns using an enhanced Xtent model. Identifying Settlement Patterns and Territories. Layers of Perception CAA 08, editado por A. Posluschny, K. Lambers y I. Herzog, pp. 245-251. Archaeopress, ciudad??.

Duffait, E. 2005. Choquequirao en el siglo XVI: etnohistoria e implicaciones arqueológicas. Bulletin de l'Institut Francais d'Études Andines 34:185-196.

Duffait, E. 2007. Réseau Routier Inca de la Cordillère de Vilcabamba (Département de Cusco, Pérou): Description, Organisation, Origines et Fonctions. Tesis doctoral, Archéologie des Amériques, Université Paris 1 Panthéon Sorbonne, Paris.

Duffait, E. 2012. Vías prehispánicas y cultos de los muertos en el norte chileno durante el periodo intermedio tardío y el horizonte tardío. Chungara Revista de Antropología Chilena 44:621-635.

Duviols, P. 1967. Un inédit de Cristóbal de Albornoz: la instrucción para descubrir todas las guacas del Piru y sus camayos y haciendas. Journal de la Société des Américanistes LVI:7-40.

Duviols, P. 1979. Un symbolisme de l'occupation, de l'aménagement et de l'exploitation de l'espace. Le monolithe huanca et sa fonction dans les Andes préhispaniques. L'Homme 19:7-31.

Earle, T.K. 1997. How Chiefs come to Power: the Political Economy in Prehistory. Stanford University Press, Stanford.

Earle, T.K., T.N. D’ Altroy, C.A. Hastorf, C. Scott, C.L. Costin, G. Russell y E. Sandefur 1987. Archaeological Field Research in the upper Mantaro, Peru, 1982-1983: Investigations of Inka Expansion and Exchange. Serie Monograph 28. Institute of Archaeology, University of California, Los Angeles.

Earls, J. e I. Silverblatt 1978. La realidad física y social en la cosmología andina. Actes du XLII Congrès International des Americanistes. Congrès du Centenaire, vol. IV, pp. 299-325. Société des Américanistes.

Espinoza Soriano, W. 1973. Colonias de mitmas múltiples en Abancay, siglos XV y XVI. Revista del Museo Nacional 39:225-300.

Favory, F., L. Nuninger y L. Sanders 2012. Intégration de concepts de géographie et d'archéologie spatiale pour l'étude des systèmes de peuplement. L'Espace Géographique 41:295-309.
Fish, S.K. 1999. Conclusions: The settlement pattern concept from an americanist perspective. En Settlement Pattern Research in the Americas: Fifty Years since Virú, editado por B.R. Billman y G.M. Feinman, pp. 203-208. Serie Smithsonian series in archaeological inquiry. Smithsonian Institution, Washington D.C.

Flores Ochoa, J. 1985. Interaction and complementarity in three zones of Cuzco. En Andean Ecology \& Civilization: An Interdisciplinary Perspective on Andean Ecological Complementarity, editado por S. Masuda, I. Shimada y C. Morris, pp. 251-276. University of Tokyo, Tokyo.

Garcilaso de la Vega, I. 1976 [1609]. Comentarios Reales de los Incas 5 y 6. Biblioteca Ayacucho, Caracas.

Godelier, M. 2007. Aux Fondements des Sociétés Humaines. Albin Michel, Paris.

Goldstein, P.S. 2000. Communities without borders: the vertical archipielago and diaspora communities in the southern Andes. En Archaeology of Communities: Anew World Perspective, editado por M.A. Canuto y J. Yeager, pp. 182-209. Routledge, London y New York.

Gonzáles de Holguín, D. 1989 [1608]. Vocabulario de la Lengua General en Todo el Perú Llamada Lengua Quechua o del Inca. UNMSM, Lima.

Grosboll, S. 1993. ... And he said in the time of the Ynga, they paid tribute and served the Ynga. En Provincial Inca: Archaeological and Ethnohistorical Assessment of the Impact of the Inca State, editado por M.A. Malpass, pp. 44-76. University of Iowa Press, Iowa City.

Guamán Poma de Ayala, F. 1615. El Primer Nueva Crónica y Buen Gobierno. Biblioteca Real de Dinamarca, Copenhague.

Guillén Guillén, E. 1980. Documentos para la historia inca de Vilcabamba: cartas de Tito Cusi Yupanqui, Martín de Pando, Diego Rodríguez de Figueroa y Antonio de Vera. III Congreso Peruano el Hombre y la Cultura Andina: Actas y Trabajos, editado por R. Matos Mendieta, vol. IV, pp. 628-653, Lima.

Guillén Guillén, E. 1984. Tres documentos inéditos para la historia de la guerra de reconquista inca. Las declaraciones de Lorenzo Manko y Diego Yuqra Tikona, servidores de Manko Inka Yupanki y de Francisco Waman Bimachi, testigos presenciales de los sucesos de 1533 a 1558. Bulletin de l'Institut Francais d'Études Andines 13:17-46.

Hampe, T.M. 1979. Relación de los encomenderos y repartimientos del Perú en 1561. Historia y Cultura 12:75-118.

Harris, O. 1997. Los límites como problema: mapas etnohistóricos de los Andes Bolivianos. En Saberes y Memorias en los Andes. In memoriam T. Saignes, editado por T. Bouysse-Cassagne, pp. 351-374. Institut Français d'Études Andines, IHEAL, ciudad??.

Hastorf, C.A. 2001. The Xauxa andean life. En Empire and Domestic Economy, editado por T.N. D'Altroy y C.A. Hastorf, pp. 315-324. Kluwer Academic Press, New York, Boston, Dordrecht, London, Moscow.

Heffernan, K. 1996. Limatambo: Archeology, History and the Regional Societies of Inca Cusco. Serie BAR International Series 644. British Archaeological Reports, Oxford. 
Hostnig, R., C. Palomino y J.-J. Decoster 2007. Proceso de Composición y Titulación de Tierras en Apurímac-Perú. Siglos $X V I-X X$. EDITATÚ, Cusco.

Hyslop, J. 1990. Inka Settlement Planning. University of Texas Press, Austin.

Isbell, W.H. 1997. Mummies and Mortuary Monuments. A Postprocesual Prehistory of Central Andean Organization. University of Texas Press, Austin.

Isbell, W.H. 2000. What we should be studying? The "imagined community" and the "natural community". En Archaeology Of Communities: Anew World Perspective, editado por M.A. Canuto y J. Yeager, pp. 243-266. Routledge, London and New York.

Itier, C. 1997. Parlons Quechua: La Langue du Cuzco. Serie Collection Parlons. L'Harmattan, Paris.

Jennings, J. y W. Yépez 2009. El Intermedio Tardío en el valle de Cotahuasi, Perú. ANDES: Boletín del Centro de Estudios Precolombinos de la Universidad de Varsovia 7:481-502. Arqueología del área centro sur andina. Actas del simposio internacional 30 de Junio - 2 de Julio de 2005, Arequipa.

Johnson, G.A. 1977. Aspects of regional analysis in archaeology. Annual Reviews of Anthropology 6:479-508.

Jouty, S. y H. Odier 1999. Le Dictionnaire de la Montagne. Arthaud, Paris.

Julien, C. 1998. La encomienda del Inca. Actas del IV Congreso Internacional de Etnohistoria, pp. 489-516. Fondo Editorial Pontificia Universidad Católica del Perú, Lima.

Julien, C. 2002. Diego Maldonado y los Chancas. Revista Andina 34:183-197.

Kendall, A. (ed.) 1984. Current Archaeological Projects in the Central Andes: Some Approaches and Results: Proceedings, 44 International Congress of Americanists, Manchester 1982. Serie BAR International Series 210. British Archaeological Reports, Oxford.

Kendall, A. 1997. Restauración de Sistemas Agrícolas Prehispánicos en la Sierra Sur, Perú: Arqueología y Tecnología Indígena en Desarrollo Rural. Cusichaca Trust, Cusco.

Kosiba, S. y A. Bauer 2013. Mapping the political landscape: Toward a GIS analysis of environmental and social difference. Journal of Archaeological Method and Theory 20:61-101.

Kowalewski, S.A. 2008. Regional settlement pattern studies. Journal of Archaeological Research 16:225-285.

Lagos Aedo, G. 1999. Historia y Arqueología de Abancay. Editorial Alpha, Cusco.

Lavallée, D. y M. Julien 1973. Les Etablissements Asto à l'époque Préhispanique. Serie Travaux de l'Institut Français d'Études Andines XV, Lima.

Lecoq, P. y T. Saintenoy 2014. The ceremonial platform called ushnu at Choqek'iraw. En Inca Ushnus: Landscape Site and Symbols in the Andes, editado por F. Meddens, C. McEwan, K. Willis y N. Branch, pp. 209-220. Archetype publications, London.

Lefebvre, H. 2000 [1974]. La Production de l'Espace. Serie Ethnosociologie. Economica, Paris.
Levy, J. y M. Lussault (eds.) 2003. Dictionnaire de la Géographie et de l'Espace des Sociétés. Belin, Paris.

Llobera, M., P. Fábrega-Álvarez y C. Parcero-Oubiña 2011. Order in movement: a GIS approach to accessibility. Journal of Archaeological Science 38:843-851.

Malpass, M.A. (ed.) 1993. Provincial Inca: Archaeological and Ethnohistorical Assessment of the Impact of the Inca State. University of Iowa Press, Iowa City.

Marcus, J. 2000. Toward an archaeology of communities. En Archaeology of Communities: Anew World Perspective, editado por M.A. Canuto y J. Yeager, pp. 231-242. Routledge, London y New York.

Martínez, G. 1983. Los dioses de los cerros en los Andes. Journal de la Société des Américanistes LXIX:85-116.

McCarthy, M. 2008. Boundaries and the archaeology of frontier zones. En Handbook of Landscape Archaeology, editado por B. David y J. Thomas, pp. 202-209 World Archaeological Congress research handbooks in archaeology. Left Coast Press, Walnut Creek.

Meddens, F. 2014. Boundaries at the roof of the world: the ushnu and divisions in political and religious space. En Inca ushnus: Landscape Site and Symbols in the Andes, editado por F. Meddens, C. McEwan, K. Willis y N. Branch, pp. 57-70. Archetype publications, London.

Mellafe, R. 1972. Consideraciones históricas sobre la visita. En Visita de la Provincia León de Huanuco en 1562. Iñigo Ortiz de Zúñiga visitador. Tomo 1: visita de las Cuatro Waranqa de los Chupachu, editado por J.V. Murra, pp. 323-344. Universidad Nacional Hermilio Valdizan, Huanuco.

Molinié Fioravanti, A. 1978. La communauté aujourd'hui. Annales Economies Sociétés Civilisations: Numéro Spécial Anthropologie Historique des Sociétés Andines 5-6:1182-1196.

Molinié Fioravanti, A. 1985. Tiempo del espacio y espacio del tiempo en los Andes. Journal de la Société des Américanistes LXXI:97-114.

Molinié Fioravanti, A. 1986-1987. El simbolismo de frontera en los Andes. Revista del Museo Nacional XLVIII:251-287.

Molinié Fioravanti, A. 1988. Sanglantes et fertiles frontières. A propos des batailles rituelles andines. Journal de la société des américanistes LXXIIV:49-70.

Moore, J.D. 1995. The archaeology of dual organization in andean south America: A theoretical review and case study. Latin American Antiquity 6:165-181.

Moreno, S.Y. y F. Salomon 1991. Reproducción y Transformación de las Sociedades Andinas Siglos XVI-XX. Serie Colección 500 años. Ediciones Abya-Yala. MLAL, Quito.

Mumford, J.R. 2012. Vertical Empire.The General Resettlement of Indians in the Colonial Andes. Duke University Press, Durham.

Murra, J.V. (ed.) 1972. Visita de la Provincia Leon de Huanuco en 1562. Iñigo Ortiz de Zúñiga visitador. Tomo 1: Visita de las Cuatro Waranqa de los Chupachu. Serie Documentos para la historia y etnología de Huánuco y la selva central. Universidad Nacional Hermilio Valdizán, Huánuco. 
Murra, J.V. 1983 [1978]. La Organización Económica del Estado Inca. Serie América Nuestra. Siglo Veintiuno, México, D.F.

Murra, J.V. 1996. El control vertical de un máximo de pisos ecológicos y el modelo en archipiélago / Quince años después: balance de la noción de archipiélago. En Comprender la Agricultura en los Andes Centrales: Perú-Bolivia, editado por P. Morlon, pp. 122-135. Institut Français d'Études Andines, Centro de Estudios Regionales Andinos Bartolomé de Las Casas, Lima.

Nash, D. 2009. Household archaeology in the Andes. Journal of Archaeological Research 17:205-261.

Nielsen, A. 2006. Pobres jefes: aspectos corporativos en las formaciones sociales pre-inkaicas de los Andes circumpuneños. En Contra La Tiranía de las Tipologías en Arqueología, editado por C. Gnecco y C.H. Langebaek, pp. 121-150. Uniandes, Ceso.

Nieves Zedeño, M. 2008. The archaeology of territory and territoriality. En Handbook of Landscape Archaeology, editado por B. David y J. Thomas, pp. 210-217. World Archaeological Congress research handbooks in archaeology. Left Coast Press, Walnut Creek.

Nuninger, L. y L. Sanders 2006. La modélisation des réseaux d'habitat en archéologie: trois expériences. M@ppemonde 83:1-28.

Palomino Flores, S. 1971. La dualidad en la organización sociocultural de algunos pueblos del área andina. Revista del Museo Nacional de Antropología y Arqueología XXXVII:231-260.

Parsons, J.R., C.M. Hastings y R. Matos Mendieta 2000. Prehispanic Settlement Patterns in the upper Mantaro and Tarma Drainages, Junín, Peru. v. 1, The Tarama-Chinchaycocha Region (pts. 1-2). Serie Memoirs of the Museum of Anthropology, Univ of Michigan 34. University of Michigan, Museum of Anthropology, Ann Arbor.

Parssinen, M. 2003. Tawantisuyu, el Estado Inca y Su Organización Política. Institut Français d'Études Andines, Pontificia Universidad Católica del Perú, Lima.

Peterson, C.E. y R.D. Drennan 2005. Communities, settlements, sites, and surveys: Regional-scale analysis of prehistoric human interaction. American Antiquity 70:5-30.

Platt, T. 1978. Symétrie en miroir: Le concept de Yanantin chez les Macha de Bolivie. Annales Economies Sociétés Civilisations: Numéro Spécial Anthropologie Historique des Sociétés Andines 33:1081-1107.

Platt, T., T. Bouysse-Cassagne y O. Harris 2006. QaraqaraCharka: Mallku, Inka y Rey en la Provincia de Charcas (Siglos XV-XVII): Historia Antropológica de una Confederación Aymara. Institut Français d'Études Andines, Plural editores, Lima, La Paz.

Politis, G.G. 2002. Acerca de la etnoarqueología en América del Sur. Horizontes Antropológicos 8:61-91.

Pumain, D. y T. Saint-Julien 2001. Les Interactions Spatiales. Flux et Changements dans l'Espace géographique. Serie Cursus Géographie. Armand Colin, Paris.

Ramírez, S.E. 1985. Social frontiers and the territorial base of Curacazgo. En Andean Ecology \& Civilization: An Interdisciplinary Perspective on Andean Ecological Complementarity, editado por S. Masuda, I. Shimada y C. Morris, pp. 423-442. University of Tokyo, Tokyo.
Ramírez, S.E. 2002. El Mundo al Revés: Contactos y Conflictos Transculturales en el Perú del Siglo XVI. Pontificia Universidad Catolica del Perú, Lima.

Ramírez, S.E. 2005. To Feed and Be Fed: the Cosmological Bases of Authority and Identity in the Andes. Stanford University Press, Stanford.

Reinhard, J. 1983. Las montañas sagradas: Un estudio etnoarqueológico de ruinas en las altas cumbres andinas. Cuadernos de Historia 3:27-62.

Renard-Casevitz, F.M., T. Saignes y A.C. Taylor 1986. L'Inca, l'Espagnol et les Sauvages: Rapports entre les Sociétés Amazoniennes et Andines du XVe au XVIIe Siècle. Serie Synthèse no 21. Editions Recherche sur les civilisations, Paris.

Rivière, G. 1983. Quadripartition et idéologie dans les communautés aymaras de Carangas (Bolivie). Bulletin de l'Institut Français d'Etudes Andines 12:41-62.

Roger, A. 1998. Court Traité du Paysage. Gallimard, Paris.

Rowe, J.H. 1946. Inca culture at the time of the Spanish conquest. En Handbook of South American Indians, editado por J.H. Steward, pp. 183-330. Smithsonian Institution, Bureau of American Ethnology, Washington D.C.

Sack, R.D. 1986. Human Territoriality. Its Theory and History. Cambridge University Press, Cambridge.

Saignes, T. 1991. Lobos y ovejas. Formación y desarrollo de los pueblos y comunidades en el sur andino (siglos XVI-XX). En Reproducción y Transformación de las Sociedades Andinas Siglos XVI-XX, editado por S.Y. Moreno y F. Salomon, pp. 91-135. Serie Colección 500 años. Ediciones Abya-Yala. MLAL, Quito.

Saintenoy, T. 2008. Choqek'iraw y el valle del Apurímac: hábitat y paisajes prehispánicos tardíos. Una investigación en curso. Bulletin de l'Institut Français d'Etudes Andines 37:553-561.

Saintenoy, T. 2011. Choqek'iraw et la Vallée de l'Apurímac: Paysages et Sociétés Préhispaniques Tardives. Tesis doctoral, Archéologie des Amériques, Université Paris 1 Panthéon Sorbonne, Paris.

Saintenoy, T. 2013. Sur le chemin d'Apurimaq: essai sur la représentation géographique du territoire dans la culture inca. L'Homme Revue Francaise d'Anthropologie 205:7-33.

Salomon, F. 1991. Tres enfoques cardinales en los actuales estudios andinos. En Reproducción y Transformación de las Sociedades Andinas Siglos XVI-XX, editado por S.Y. Moreno y F. Salomon, pp. 7-28. Serie Colección 500 años. Ediciones ABYA-YALA. MLAL, Quito.

Salomon, F. 1995. The beautifull grandparents: andean ancestors shrines and mortuary ritual as seen through colonial records En Tombs for the Living, editado por T.D. Dillehay, pp. 315-354. Dumbarton Oaks, Washington, D.C.

Sanhueza, C.T. 2008. Territorios, prácticas rituales y demarcación del espacio en Tarapacá en el siglo XVI. Boletín del Museo Chileno de Arte Precolombino 13:57-75.

Santo Tomás, F.D.d. 1951 [1560]. Lexicón o Vocabulario de la Lengua General del Perú, Compuesto por el Maestro Fray Domingo de Santo Tomas. Edición facsimilar publicada, con un prólogo, por Raúl Porras Barrenechea. Universidad Nacional Mayor de San Marcos, Publicaciones del cuarto centenario, Lima. 
Schjellerup, I. 2005. Incas y Españoles en la conquista de Chachapoyas. Pontificia Universidad Católica del Perú, Institut Français d'Études Andines, Lima.

Snead, J.E., C.L. Erickson y J.A. Darling (eds.) 2009. Landscapes of Movement. Trails, Paths and Roads in Anthropological Perspective. University of Pennsylvania Museum of Archaeology and Anthropology, Philadephia.

Stanish, C. 2001. Regional research on the Inca. Journal of Archaeological Research 9:213-241.

Stanish, C. y B.S. Bauer 2007. Pilgrimage and the geography of power in the inka empire. En Variations in the Expression of Inka Power, editado por R.L. Burger, C. Morris y R. Matos Mendieta, pp. 45-84. Dumbarton Oaks research library and collection, Harvard university press, Washington D.C.

Stanish, C., E. De La Vega y K.L. Frye 1993. Domestic architecture on Lupaqa area sites in the departement of Puno. En Domestic Architecture, Ethnicity and Complementarity in the South-Central Andes, editado por M. Aldenderfer, pp. 83-93. University of Iowa Press, Iowa City.

Taylor, G. y F.d. Avila 1980. Rites et traditions de Huarochirí: manuscrit quechua du début du 17e siècle. Serie Ethnolinguistique amérindienne. L'Harmattan, Paris.

Testart, A. 2005. Eléments de Classification des Sociétés. Editions Errante, Paris.

Tobler, W. 1993. Three Presentations on Geographical Analysis and Modeling : 1) Non-Isotropic Modeling 2) Speculations on the Geometry of Geography 3) Global Spatial Analysis. University of California. National Center for Geographic Information and Analysis. Technical Report 93-1.

Thomas, J. 2008. Archaeology, landscape and dwelling. En Handbook of Landscape Archaeology, editado por B. David y J. Thomas, pp. 300-306. Left Coast Press, Walnut Creek.

Thompson, L.G., E. Mosley-Thompson, J. Bolzan y B. Koci 1985. A 1500-Year record of tropical precipitation in ice cores from the Quelccaya Ice Cap, Peru. Science 229:971-973.

Trigger, B.G. 1967. Settlement archaeology: its goals and promise. American Antiquity 32:149-160.

Vaca de Castro, L. 1989 [1543]. Ordenanza de Tambos. Distancias de unos a otros. Modo de cargar a los indios y obligaciones de las justicias respectivas. Hecho en la ciudad del Cusco el 31 de mayo de 1543. Boletín de la Sociedad Geográfica de Lima 104:221-233.

Van Buren, M. 1996. Rethinking the Vertical Archipelago: Ethnicity, exchange, and history in the South Central Andes. American Anthropologist 98:338-351.
Van Buren, M., P. Bürgi y P.M. Rice 1993. Torata alta: a late highland settlement in the Osmore Drainage. En Domestic Architecture, Ethnicity and Complementarity in the South-Central Andes, editado por M. Aldenderfer, pp. 136-146. University of Iowa Press, Iowa City.

Van de Guchte, M. 1999. The Inca cognition of landscape: Archaeology, ethnohistory and the aesthetic of alterity. En Archaeologies of Landscape, editado por A.B. Knapp y W. Ashmore, pp. 149-168. Blackwell Publishers, Oxford.

Varón Gabai, R. 1998. Las encomiendas de Hernando Pizarro. Actas del IV Congreso Internacional de Etnohistoria, vol. 2, pp. 535-549. Fondo editorial Pontificia Universidad Catolica del Perú, Lima.

Wachtel, N. 1974. La réciprocité et l'Etat inca: de Karl Polanyi à John V. Murra. Annales Economies Sociétés Civilisations 6:1346-1355.

Wachtel, N. 1980. Les mitimas de la vallée de Cochabamba. La politique de colonisation de Huayna capac. Journal de la Société des Américanistes 67:297-324.

Wachtel, N. 1992 [1971]. La Vision des Vaincus. Editions Gallimard, Paris.

Webster, S.S. 2005 [1983]. Una comunidad quechua indígena en la explotación de múltiples zonas ecológicas. En Q'ero, el Último Ayllu Inka. Homenaje a Oscar Núñez del Prado y a la Expedición Científica de la UNSAAC a la Nación Q'ero en 1955, editado por J. Flores Ochoa, J. Núñez del Prado y M. Castillo Farfán, pp. 103-122. INC, UNMSM, Cuzco.

Wernke, S.A. 2006. The politics of community and Inka statecraft in the Colca Valley, Peru. Latin American Antiquity 17:177-208.

Wernke, S.A. 2009. La interfaz política-ecológica en el valle del Colca durante la época incaica. ANDES: Boletín del Centro de Estudios Precolombinos de la Universidad de Varsovia 7: Arqueología del área centro sur andina: Actas del simposio internacional 30 de Junio - 2 de Julio de 2005, pp. 177-208. Arequipa.

Wernke, S.A. 2013. Negotiated Settlements: Andean Communities and Landscapes Under Inca and Spanish Colonialism. University Press of Florida, Gainesville.

Yamamoto, N. 1985. The ecological complementarity of agropastoralism: some comments. En An Interdisciplinary Perspective on Andean Ecological Complementarity, editado por S. Masuda, I. Shimada y C. Morris, pp. 85-99. University of Tokyo, Tokyo.

Zuidema, T. 2010. El Calendario Inca. Tiempo y Espacio en la Organización Ritual del Cuzco. La idea del pasado. Fondo editorial del congreso del Perú, Fondo editorial PUCP, Lima.

\section{Notas}

1 Los efectos de la Anomalía Climática Medieval han sido variables en los Andes Centrales. En la cordillera sur-oriental del Perú, nuestra zona de estudio, tanto los indicadores globales (nevados) como locales (sedimentos lacustres) coinciden en señalar una fase de calentamiento combinada con una baja significativa del régimen pluvial
(Chepstow-Lusty et al. 2003; Thompson et al. 1985). En este contexto, se evalúa una variación positiva de unos $150 \mathrm{~m}$ del gradiente climático y consecuentemente del escalonamiento ecológico.

2 Desde la época colonial temprana y a veces hasta hoy, las provincias incas constituyen generalmente el prototipo 
de los territorios de las formaciones étnicas preincas (Parssinen 2003; Rowe 1946). Pero debido al carácter fundamentalmente político (y por lo tanto coyuntural) de las formaciones territoriales étnicas (Barth 1998[1969]; Sack 1986), resulta problemático determinar, más allá del grado de reordenamiento socioterritorial de una provincia, el impacto efectivo del imperialismo inca sobre la perennidad y la reformulación de las identidades asociadas a las formaciones socioespaciales preexistentes. De hecho, los archivos administrativos coloniales dan a menudo cuenta de realidades más complejas en cuanto a las composiciones étnicas y/o lingüísticas de los territorios heredados del Tawantinsuyu -a menudo alejadas de los clichés esencialistas esbozados en las crónicas-(BouysseCassagne 1975; Mellafe 1972).

3 En la mayoría de los estudios, la ocupación de los pueblos del Intermedio Tardío durante Horizonte Tardío solo ha sido evaluada según la presencia/ausencia de cultura material inca, lo que constituye un indicador problemático en ausencia de fechados de contextos estratigráficos.

4 En el valle de Cuzco no existen claras evidencias de un abandono masivo de los asentamientos habitacionales del PIT durante el proceso de formación del Estado y del desarrollo urbano del Cuzco (Bauer y Covey 2002). En los valles circundantes del Vilcanota y del Apurímac (en la región de Paruro), el patrón de asentamiento habitacional no experimentó grandes cambios, en margen de la formación de los dominios incas. En Limatambo, Curahuasi y Abancay, los estudios arqueológicos tampoco evidencian el abandono de los pueblos del Intermedio Tardío, a pesar de que las fuentes etnohistóricas indiquen movimientos poblacionales en estas regiones donde se identificaron, por lo demás, varios yacimientos del Horizonte Tardío relacionados con la edificación de tampu a lo largo de qhapaq ñan y con la implantación de colonias en el fondo del valle del Apurímac es producto del reordenamiento territorial inca (Cieza 1946[1553]; Espinoza Soriano 1973; Heffernan 1996; Lagos Aedo 1999; Vaca de Castro 1989[1543]). En la provincia Chanca de Andahuaylas, aunque las fechas radiométricas de los asentamientos habitacionales en cumbre sitúen su ocupación durante los primeros siglos del Intermedio Tardío, los mismos asentamientos suelen exhibir cerámica inca (Bauer et al 2010). En la cordillera de Vilcabamba la mayoría de los asentamientos habitacionales del Intermedio Tardío del valle de Cusichaca exhiben también cerámica inca en superficie (Kendall 1997). En resumen, el conjunto de datos de patrones de asentamiento disponibles evidencia que, a pesar del masivo reacondicionamiento territorial inca de la cordillera suroriental, la formación del Estado inca y su desarrollo imperial no produjo el abandono masivo de los asentamientos habitacionales de altura originarios del periodo Intermedio Tardío. Documentar el proceso de abandono de estos asentamientos habitacionales requiere pues mayores investigaciones específicas.

5 Si nos referimos a las herencias etnográficas, la mayoría de los acondicionamientos arquitectónicos debían ser emprendidos y realizados de manera corporativa: ya sea que se tratase de una vivienda o de infraestructuras agropastoriles de envergadura, los trabajos -regidos por lógicas de reciprocidad-reunían a colectivos más o menos extensos entre la comunidad.
6 Ciertas visitas consignan censos detallados de los ayllu en diversas escalas: de su composición demográfica y étnica, así como de las grandes líneas de su estructura sociopolítica (Diez de San Miguel et al. 1964; Murra 1972). Pero estos datos son de naturaleza administrativa y se limitan generalmente a relaciones de tributarios del sistema de explotación colonial inca y español. Asimismo, aun cuando las visitas más detalladas y los archivos de litigios registran pueblos y campos, estos documentos fragmentarios no permiten por sí solos determinar de manera satisfactoria la estructura territorial indígena, para lo cual es imprescindible considerar los datos arqueológicos (Wernke 2006).

7 En el contexto del poblamiento serrano prehispánico tardío, parece ser que los jefes no pertenecían a una clase social privilegiada desde el punto de vista material. Como lo atestiguan los archivos coloniales tempranos, el curaca de una comunidad -“quien asignaba las tareas" (Itier 1997) disponía aparentemente de un poder moderado y contextual que descansaba sobre su posición genealógica en el seno de los linajes, su generosidad política, su capacidad de administración socioeconómica, su autoridad ritual y/o su carisma guerrero; todo ello estaba destinado a conseguir que los grupos domésticos se unan a su proyecto comunitario que garantizaba el bienestar social (Earle 1997; Nielsen 2006).

8 Ayllu es el término de origen prehispánico que designa de manera genérica a la comunidad rural andina. En las etnografías, el ayllu es definido, según su contexto histórico y regional, de acuerdo con criterios relacionados con la ancestralidad, el parentesco, la economía campesina, el territorio, la autoridad de un jefe y/o el compromiso ceremonial. Los estudios muestran que se trata de una categoría multiescalar muy flexible que designa diferentes niveles de la segmentación sociopolítica piramidal: desde el grupo doméstico hasta los colectivos de miles de individuos (Molinié Fioravanti 1986-1987; Platt 1978; Saignes 1991; Wachtel 1974). En el contexto de las formaciones socioterritoriales descritas en las crónicas, el ayllu hace a menudo referencia a un linaje basado en una ancestralidad ficticia de tipo héroe fundador (Rowe 1946; Salomon 1995).

9 "Contrafuerte" designa un cordón montañoso lateral que parece servir de apoyo a una cordillera principal, mientras "espolón" se refiere a los espolones laterales de las laderas de dichos cordones montañosos. Los relieves sinclinales entre dos contrafuertes son "valles" y los localizados entre espolones son "quebradas" (Jouty et Odier, 1999: 185). Esta distinción identifica dos geoformas de distintas escalas, las cuales ofrecen condiciones diferenciadas para el asentamiento en este escenario fisiográfico montañoso extremo.

10 Para la simulación del camino óptimo se usó el algoritmo anisotrópico de Tobler (1993), que constituye un estándar genérico para dicho de tipo de análisis teórico de la movilidad pedestre en función de la pendiente (Llobera 2011).

11 Hoy aún es común que la práctica ritual de los lugares significativos (y por ende constitutivos) de los territorios partícipes fundamentalmente en la reproducción de las comunidades (Abercrombie 2006 [1998]; Allen 2008). Porque como escribe Debarbieux (2003), "el territorio posee una notable dimensión identitaria: es partícipe siempre de una visión del mundo y de una representación autorreferenciada 
e identitaria del grupo que la construye. En otras palabras, el grupo se muestra por el territorio que reivindica, por las representaciones que construye de él y comunica".

12 En un radio de un medio día de caminata alrededor de Choqek'iraw solo existe una aglomeración de recintos circulares. Se localiza en el sitio llamado Pajonal en la ladera norte del cerro de Choqek'iraw. Debido a su cercanía del palacio y a su asociación con infraestructuras agrícolas incas, así como por su localización atípica por un asentamiento habitacional en la región, postulamos la hipótesis que Pajonal podría corresponder a un asentamiento de mitima y/o yana del dominio real. Aparte de Pajonal, los asentamientos habitacionales con arquitectura típica de las llaqtas del valle del Apurímac se encuentran a un día de caminata de Choqek'iraw en la región de Quinualla y en la zona de Chaupiloma en la cuenca del río Yanama, aunque no existen ahí grandes asentamientos.

13 En las zonas de prospección (fuera del dominio real de Choqek'iraw), edificios de estilo inca fueron identificados en tan solo cinco sitios. Solo uno de estos corresponde a un asentamiento inca: Pinkoyunka en el valle de Arma. En
Pumachaka y Pasaje, edificios incas se encuentran junto con sistemas agrícolas en terrazas fluviales del Apurímac. En Inkawasi y en Villar, un gran edificio de tipo kallanka fue implantado en medio de una aglomeración de viviendas circulares. Respecto de la cerámica, solo el $2 \%$ de la muestra recolectada durante las prospecciones de 2007 corresponde a fragmentos afiliados al estilo inca (en ca. $10 \%$ de los asentamientos habitacionales registrados) (Saintenoy 2011).

14 Durante las prospecciones de 2007, muestras de cerámica fueron recolectadas sistemáticamente: 700 fragmentos en 44 sitios. Mientras se realizó una recolección no estratificada de fragmentos preferencialmente diagnósticos, los fragmentos decorados representan tan solo $10 \%$ del corpus. La caracterización petrográfica-según observaciones macroconsolidadas mediante análisis de láminas delgadas de ejemplares típicos- permitió elaborar una tipología de pastas considerando características composicionales y tecnológicas. La proporción de mica en las pastas resultó un indicador claro de la producción independiente de la cerámica más común de ambos lados del valle del Apurímac (Saintenoy 2011). 